\title{
Optimization and Damping Performance of a Coal-Fired Power Plant Building Equipped with Multiple Coal Bucket Dampers
}

\author{
Ling-Yun Peng $\left(\mathbb{D}\right.$, Ying-Jie Kang $\mathbb{D}^{D}$, Zong-Rui Lai $\left(\mathbb{D}\right.$, and Yu-Ke Deng ${ }^{(D)}$ \\ Beijing Key Lab of Earthquake Engineering and Structural Retrofit, Beijing University of Technology, Beijing 100124, China \\ Correspondence should be addressed to Ling-Yun Peng; ply@bjut.edu.cn
}

Received 5 December 2017; Revised 28 March 2018; Accepted 5 April 2018; Published 2 May 2018

Academic Editor: Lyan-Ywan Lu

Copyright ( $) 2018$ Ling-Yun Peng et al. This is an open access article distributed under the Creative Commons Attribution License, which permits unrestricted use, distribution, and reproduction in any medium, provided the original work is properly cited.

\begin{abstract}
A parameter optimization design method is proposed for multiple coal bucket dampers (CBDs) to reduce the seismic response of coal-fired power plants. To test the damping effect of the optimized CBDs, a 1:30 scale shaking table test model of a power plant structure was fabricated. A comparative testing program was conducted using three seismic excitations on a model with and without CBDs. A finite element analysis model, replicating the conditions of the shaking table test, was constructed for comparison, and the shock absorption effects of CBDs subjected to 22 groups of far-field seismic action and 28 groups of near-field seismic action were analyzed. Finally, the influence of changes in the structural period on the seismic response of the CBDequipped structure was studied. The results indicate that the use of CBDs in a coal-fired power plant structure, based on an optimization design method for multiple-tuned mass dampers (MTMDs), results in a significant reduction in the structure displacement response, displays a certain discreteness under different excitations, and maintains a certain damping stability even as the structural period changes. Overall, the use of CBDs is a promising prospect for improving the seismic performance of coalfired power plant structures.
\end{abstract}

\section{Introduction}

In 2016, burning of coal accounted for $71.60 \%$ of all power generation in China, and this dominant position of coal-fired power generation is unlikely to change in the near future [1]. In 2011, nuclear power plants in Japan were widely shut down after the Fukushima crisis, leading to proposals for the massive expansion of coal-fired power plants there. In addition, coal-fired power generation also plays a very important role in India, the United States, and Turkey, as well as in many other countries [2]. As critical lifeline infrastructure, the seismic safety of coal-fired power plants is very important. In the 1970s, the concept of structural vibration control was proposed for the first time to improve the safety and reliability of structures under excitation [3]. The structure of a typical coal-fired power plant often consists of a reinforced concrete frame-bent structure with many weak links [4], so it is advantageous to evaluate coal plants with an eye toward structure vibration control technology.

As early as 1956, Den Hartog provided a basic equation for the behavior of a tuned mass damper (TMD) under harmonic excitation [5]. Subsequently, the optimal design parameters for the use of a TMD under different excitation conditions have been supplemented and developed $[6,7]$. In the field of civil engineering, the use of TMDs has been widely studied and developed as a vibration control technology $[8,9]$. The range of application of TMD technology includes super high-rise structures [10], towering structures [11], and large span structures [12]. However, a single TMD has some disadvantages, including frequency sensitivity and poor robustness. Therefore, double-tuned mass dampers and multiple-tuned mass dampers (MTMDs) were proposed to improve the effectiveness of TMD behavior [13]. Subsequently, results have shown that the use of MTMDs provides improved shock absorption and seismic stability over a single TMD [14-18]. The application of MTMDs is divided into different variants according to the different combinations of stiffness coefficients, damping coefficients, and mass and damping ratios of each component TMD. Despite this diversity in application, results indicate that all types of MTMD have nearly the same effectiveness in reducing vibration and exhibit similar robustness under 
optimal parameters [19-22]. In recent years, different approaches for the optimal design of MTMD systems have been proposed [20-25]. The minimization of the dynamic magnification factors for displacement and acceleration of the MTMD-equipped structure has typically been selected as the criterion for optimization [20]. Considering the displacement of each MTMD unit relative to its installed position (the stroke), a two-stage optimization procedure for the design of MTMD parameters has been developed. Theoretical analysis and experimental results have indicated that the stroke of a TMD can be significantly reduced with little sacrifice in the control and effectiveness of the structural response $[23,24]$. More recently, a new design method has been proposed that can significantly enhance system robustness with only slight detriment to structural control effectiveness [25].

Based on the concept of structural vibration control, TMD technology has been proposed for the seismic design of large coal-fired power plant buildings. A unique coal bucket damper (CBD) technology is applied to the structure using the mass of coal buckets as the mass of the TMD. This approach differs from traditional TMD applications, which rely upon the addition of mass to a structure to function. At the present stage, the main methods for implementing the proposed CBD technology include suspension and support $[2,26,27]$. In a coal-fired power plant, the coal buckets are located at a relatively high elevation in the structure, an elevation close to the optimal placement of a TMD [28-30]. The ratio of coal bucket mass to the total structural mass can reach about $10 \%$-a considerable mass ratio for a tuned mass damper device-and thus the mass of coal in the buckets can be used to provide a significant degree of vibration reduction. Suspension-type CBDs and pendulum-tuned mass dampers (PTMDs) have similar operational parameters in vibration damping [31]. Though the support system of a CBD is connected to the main structure by bearings with low horizontal stiffness and high damping coefficients, fundamentally speaking, both suspension-type and pendulum-type CBDs are classified as forms of tuned damping control [32]. Detailed analytical work using a CBD as a TMD has already been performed in the literature [2], and the results indicate that a CBD can significantly reduce the earthquake response of the larger structure in which it is incorporated. However, the behavior of this larger structure itself has not yet been analyzed with consideration of the contribution of multiple coal bucket dampers.

Based on the reductive vibration theory used to model MTMD systems, an optimized design method for a coal-fired power plant building using CBDs as an MTMD system is proposed in this paper. To this end, shaking table tests of reinforced concrete frames equipped with optimized CBDs are conducted. Simple pendulum and horizontal elastic elements are used to provide resilient restoration force for the CBDs. Considering the influence of seismic wave randomness [33] and seismic wave intensity [34] on CBD behavior, three sets of seismic wave test conditions at different intensities are established and applied to the frames. By comparing the dynamic responses of structures with and without CBDs, the vibration reduction effectiveness of the CBDs is obtained. At

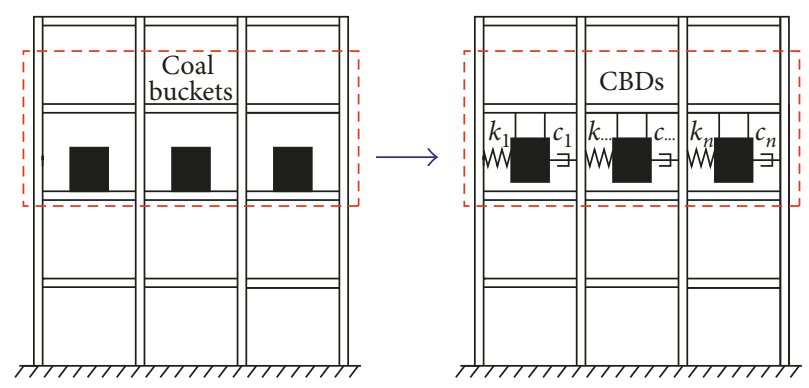

Figure 1: Simplified model of a coal-fired power plant building. (a) Traditional power plant. (b) Power plant with CBDs.

the same time, a finite element model corresponding to the test model is constructed. The seismic performance of the CBDequipped structure is analyzed under 22 sets of far-field seismic action and 28 sets of near-field seismic action. Finally, the seismic stability of the CBD-equipped structure after fundamental periodic change is analyzed, and the behavior of the proposed system is compared to that of the shaking table tests to provide conclusions on its effectiveness.

\section{Optimization Method and Design of Experimental Model}

2.1. Parameter Optimization of CBD Structure. Figure 1 depicts the locations of coal buckets fixed to the frame of a traditional power plant. The proposed CBD technology removes this fixed connection by suspending or supporting the coal buckets. Accordingly, elastic and damping elements connecting the structure to the coal buckets are used to adjust the oscillation frequency and additional damping of the buckets, respectively. To optimize the damping effect of the CBDs, it is necessary to optimize the design of the dynamic characteristics of the CBDs.

2.1.1. Displacement Response Transfer Function. The power plant structure is simplified to a shear model with $N$ degrees of freedom. The proposed CBDs consisting of $m$ CBD units are arranged on the $j$ th story. The dynamic equations of the model with CBDs under the base acceleration excitation $\ddot{x}_{\mathrm{g}}(t)$ are as follows:

$$
\begin{aligned}
\mathbf{M} \ddot{\mathbf{x}}(t)+\mathbf{C} \dot{\mathbf{x}}(t)+\mathbf{K} \mathbf{x}(t) & =\mathbf{F}_{\mathrm{CBDs}}-\mathbf{M I}_{N} \ddot{x}_{g}(t), \\
\overline{\mathbf{M}} \ddot{\overline{\mathbf{x}}}(t)+\overline{\mathbf{M}} \mathbf{I}_{m} \ddot{x}_{j}(t) & \\
+\overline{\mathbf{C}} \dot{\mathbf{x}}(t)+\overline{\mathbf{K}} \overline{\mathbf{x}}(t) & =-\overline{\mathbf{M}} \mathbf{I}_{m} \ddot{x}_{\mathrm{g}}(t), \\
\mathbf{F}_{\mathrm{CBDs}} & =\mathbf{I}_{m}^{T}(\overline{\mathbf{C}} \dot{\overline{\mathbf{x}}}(t)+\overline{\mathbf{K}} \overline{\mathbf{x}}(t)) \mathbf{D}_{j} .
\end{aligned}
$$

In (1), $\mathbf{M}, \mathbf{C}$, and $\mathbf{K}$ are the mass matrix, damping matrix, and stiffness matrix of the main structure, respectively, and these matrices are of dimensions $N \times N$. The functions $\mathbf{x}(t)$, $\dot{\mathbf{x}}(t)$, and $\ddot{\mathbf{x}}(t)$ are the displacement, velocity, and acceleration vectors of the main structure, respectively, with respect to the ground and are all of $N$ dimensions. The variable $\mathbf{I}_{N}$ represents an $N$-dimensional unit vector. In (2), $\overline{\mathbf{M}}, \overline{\mathbf{C}}$, and $\overline{\mathbf{K}}$ 
are the mass matrix, damping matrix, and stiffness matrix, respectively, of the CBDs, and these matrices are of dimensions $m \times m$. The functions $\overline{\mathbf{x}}(t), \dot{\overline{\mathbf{x}}}(t)$, and $\ddot{\overline{\mathbf{x}}}(t)$ are the displacement, velocity, and acceleration vectors, respectively, of the CBDs with respect to the main structure, and they are all of $m$ dimensions. The variable $\mathbf{I}_{m}$ is an $m$-dimensional unit vector. The function $\ddot{x}_{j}(t)$ is the acceleration of the $j$ th story of the structure, $\mathbf{F}_{\mathrm{CBDs}}$ is the force acting on the main structure from the CBDs, and $\mathbf{D}_{j}=[0 \cdots 010 \cdots 0]^{T}$ is the position vector of the CBDs in which the $j$ th element is 1 , and all other elements are 0 .

Equation (3) can also be written as

$$
\mathbf{F}_{\mathrm{CBDs}}=\mathbf{D}_{j} \sum_{p=1}^{m}\left(c_{p} \dot{\bar{x}}_{p}+k_{p} \bar{x}_{p}\right),
$$

where $k_{p}$ and $c_{p}$ are the stiffness and damping coefficient, respectively, of the $p$ th CBD. The variables $\bar{x}_{p}$ and $\dot{\bar{x}}_{p}$ are the displacement and velocity, respectively, of the $p$ th CBD.

The vibration mode of the structural system is then decomposed and the vibration matrix $\boldsymbol{\Phi}$ is obtained, where $\mathbf{q}(t)$ is the $N \times 1$ modal displacement vector. Substituting $\mathbf{x}(t)=\boldsymbol{\Phi} \mathbf{q}(t)$ into (1) and premultiplying the two sides of the building part by $\Phi^{T}$ yield

$$
\mathbf{M}^{*} \ddot{\mathbf{q}}(t)+\mathbf{C}^{*} \dot{\mathbf{q}}(t)+\mathbf{K}^{*} \mathbf{q}(t)=\boldsymbol{\Phi}^{T} \mathbf{F}_{\mathrm{CBDs}}-\boldsymbol{\Phi}^{T} \mathbf{M I}_{N} \ddot{x}_{\mathrm{g}}(t),
$$

where $\mathbf{M}^{*}, \mathbf{C}^{*}$, and $\mathbf{K}^{*}$ are the structural modal mass, structural modal damping, and structural mode stiffness matrix, respectively. The dynamic equilibrium of the $n$th order mode is

$$
\begin{aligned}
& M_{n} \ddot{q}_{n}(t)+C_{n} \dot{q}_{n}(t)+K_{n} q_{n}(t) \\
& \quad=\phi_{n j} \sum_{p=1}^{m}\left(c_{p} \dot{\bar{x}}_{p}+k_{p} \bar{x}_{p}\right)-\boldsymbol{\Phi}_{n}^{T} \mathbf{M} \mathbf{I}_{N} \ddot{x}_{\mathrm{g}}(t),
\end{aligned}
$$

where $M_{n}, C_{n}$, and $K_{n}$ are the $n$th order structural modal mass, structural modal damping, and structural mode stiffness, respectively. The variable $q_{n}(t)$ represents the generalized coordinates of the $n$th order vibration mode, $\Phi_{n}$ is the $n$th mode vector, and $\phi_{n j}$ is the $j$ th element of $\boldsymbol{\Phi}_{n}$.

If the $n$th mode is the main mode of vibration control, substituting $\ddot{x}_{j}(t)=\phi_{n j} \ddot{q}_{n}(t)$ into (2) yields the following equation:

$$
\overline{\mathbf{M}} \ddot{\mathbf{x}}(t)+\overline{\mathbf{M}} \mathbf{I}_{m} \phi_{n j} \ddot{q}_{n}(t)+\overline{\mathbf{C}} \dot{\overline{\mathbf{x}}}(t)+\overline{\mathbf{K}} \overline{\mathbf{x}}(t)=-\overline{\mathbf{M}} \mathbf{I}_{m} \ddot{x}_{\mathrm{g}}(t) .
$$

The new system of dynamic equations describing the main vibration modes and the MTMD is composed of (6) and (7). After setting $\mathbf{U}(t)=\left[\begin{array}{l}q_{n}(t) \\ \overline{\mathbf{x}}(t)\end{array}\right]$, these two equations
become

$$
\widetilde{\mathbf{M}} \ddot{\mathbf{U}}(t)+\widetilde{\mathbf{C}} \dot{\mathbf{U}}(t)+\widetilde{\mathbf{K}} \mathbf{U}(t)=\left\{\begin{array}{l}
-\boldsymbol{\Phi}_{n}^{T} \mathbf{M I}_{N} \\
-\overline{\mathbf{M I}}_{m}
\end{array}\right\} \ddot{x}_{\mathrm{g}}(t),
$$

in which

$$
\begin{aligned}
& \widetilde{\mathbf{M}}=\left[\begin{array}{c}
M_{n} \\
\overline{\mathbf{M I}}_{m} \phi_{n j} \\
\mathbf{M}
\end{array}\right], \\
& \widetilde{\mathbf{C}}=\left[\begin{array}{c}
C_{n}-\phi_{n j} c_{1}-\phi_{n j} c_{2}-\cdots-\phi_{n j} c_{m} \\
0 \\
\overline{\mathbf{C}}
\end{array}\right] \text {, } \\
& \widetilde{\mathbf{K}}=\left[\begin{array}{c}
K_{n}-\phi_{n j} k_{1}-\phi_{n j} k_{2}-\cdots-\phi_{n j} k_{m} \\
0 \\
\overline{\mathbf{K}}
\end{array}\right] .
\end{aligned}
$$

According to the frequency-preserving property of a linear system, setting $\ddot{x}_{\mathrm{g}}(t)=e^{i \omega t}$ and substituting $\mathbf{U}(t)=$ $\mathbf{y}(\omega) e^{i \omega t}$ into (8), in which $\mathbf{y}(\omega)$ is the transfer function of the system, the equation becomes

$$
\begin{aligned}
-\omega^{2} \widetilde{\mathbf{M}} \mathbf{y}(\omega) e^{i \omega t} & +i \omega \widetilde{\mathbf{C}} \mathbf{y}(\omega) e^{i \omega t} \\
& +\widetilde{\mathbf{K}} \mathbf{y}(\omega) e^{i \omega t}=\left\{\begin{array}{c}
-\boldsymbol{\Phi}_{n}^{T} \mathbf{M I}_{N} \\
-\overline{\mathbf{M}} \mathbf{I}_{m}
\end{array}\right\} e^{i \omega t} .
\end{aligned}
$$

By setting $\Gamma=\left\{\begin{array}{l}-\boldsymbol{\Phi}_{n}^{T} \mathbf{M I}_{N} \\ -\mathbf{M I}_{m}\end{array}\right\}, \mathbf{y}(\omega)$ can be obtained by using (10) as follows:

$$
\mathbf{y}(\omega)=\left(-\omega^{2} \widetilde{\mathbf{M}}+i \omega \widetilde{\mathbf{C}}+\widetilde{\mathbf{K}}\right)^{-1} \Gamma .
$$

The generalized coordinate transfer function of the $n$th order vibration mode of the main structure is the first element of $\mathbf{y}(\omega)$, which can be obtained by calculation as follows [21]:

$$
\begin{aligned}
\mathbf{y}_{1}(\omega) & =\frac{-\eta_{n}-\phi_{n j} Z(\omega)}{-\omega^{2}+2 i \xi_{n} \omega \omega_{n}+\omega_{n}^{2}-\omega^{2} \phi_{n j}^{2} Z(\omega)}, \\
Z(\omega) & =\sum_{p=1}^{m} \frac{m_{p}}{M_{n}} \frac{2 i \xi_{p} \omega \omega_{p}+\omega_{p}^{2}}{-\omega^{2}+2 i \xi_{p} \omega \omega_{p}+\omega_{p}^{2}},
\end{aligned}
$$

in which

$$
\begin{aligned}
& \eta_{n}=\frac{\boldsymbol{\Phi}_{n}^{T} \mathbf{M I}_{N}}{M_{n}}, \\
& \omega_{n}=\sqrt{\frac{K_{n}}{M_{n}}}, \\
& \xi_{n}=\frac{C_{n}}{2 \omega_{n} M_{n}}, \\
& \omega_{p}=\sqrt{\frac{k_{p}}{m_{p}}}, \\
& \xi_{p}=\frac{c_{p}}{2 \omega_{p} m_{p}},
\end{aligned}
$$

where $\eta_{n}, \omega_{n}$, and $\xi_{n}$ are the $n$th mode participation factor, structural modal frequency, and structural mode damping ratio, respectively, and $m_{p}, \omega_{p}$, and $\xi_{p}$ are the $p$ th CBD mass, frequency, and damping ratio, respectively. 


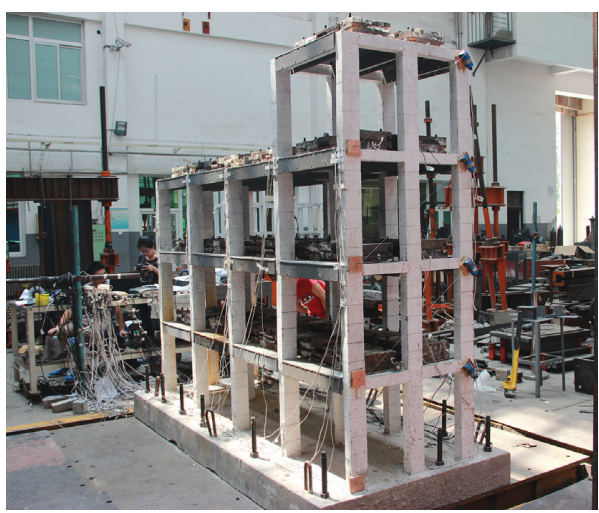

(a)
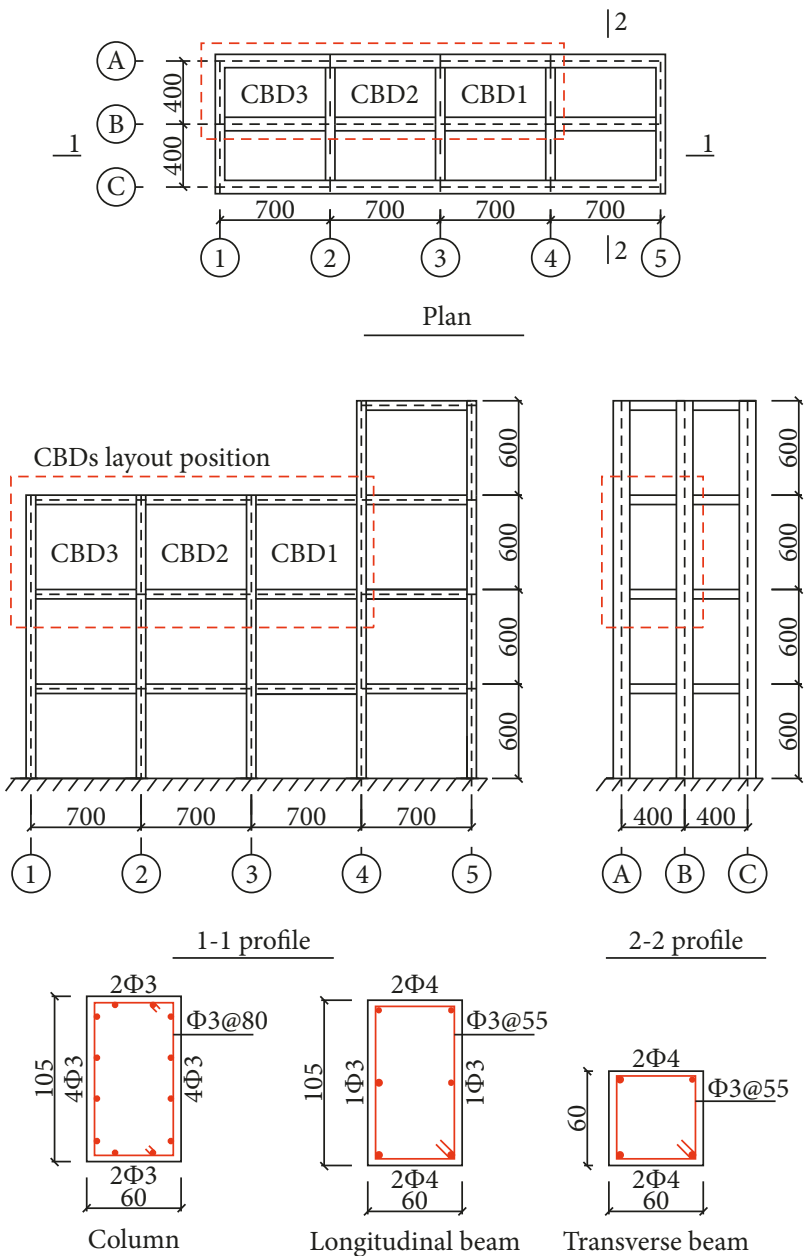

2-2 profile

Section reinforcement

(b)

FIGURE 2: (a) Shaking table test model. (b) Test structure model dimensions (in $\mathrm{mm}$ ) where $\mathrm{CBD} 1, \mathrm{CBD} 2$, and $\mathrm{CBD} 3$ are the three CBDs.

2.1.2. Objective Function of Optimum Design. Considering that ground motion consists of random vibrations, the variance of the structural displacement response is solved under the stochastic model of the earthquake ground motion, and the minimum variance is used as the objective function of the optimal parameter. Assuming that the seismic excitation is a

TABLE 1: Detailed similarity coefficients.

\begin{tabular}{lcc}
\hline Physical quantity & Dimension & Scaling coefficient \\
\hline Size & {$[\mathrm{L}]$} & $S_{L}=1 / 30$ \\
Young's modulus & {$[\mathrm{FL}-2]$} & $S_{E}=1 / 2$ \\
Effective mass density & {$[\mathrm{FL}-4 \mathrm{~T} 2]$} & $S_{\rho_{\mathrm{e}}}=4.24$ \\
Time & {$[\mathrm{T}]$} & $S_{T}=0.097$ \\
Frequency & {$[\mathrm{T}-1]$} & $S_{\omega}=10.3$ \\
Acceleration & {$[\mathrm{LT}-2]$} & $S_{a}=3.5$ \\
\hline
\end{tabular}

stationary random white-noise process and that $S_{0}$ is the power spectrum density of seismic waves, the generalized coordinate response variance of the main structure mode can be expressed as follows [33]:

$$
\sigma_{q_{n}}^{2}=\int_{-\infty}^{\infty} S_{q_{n}}(\omega) d \omega=\int_{-\infty}^{\infty}\left|\mathbf{y}_{1}(\omega)\right|^{2} S_{0} d \omega
$$

In thermal power plant construction, the mass of all coal scuttles is the same, and the damping ratios of all CBDs are designed to be equal, that is, $m_{p}=m_{\mathrm{d}}$ and $\xi_{p}=\xi_{\mathrm{d}}$, where $p=1,2, \ldots, m$. The variable $\beta \omega_{n}$ is the frequency ratio convergence, and the frequency ratio interval is given by $\beta \omega_{n} /(m-1)$. The variable $\omega_{\mathrm{d}}$ represents the average frequency of the CBDs, and $\Delta$ is the deviation between the average frequency of the CBDs and the frequency of the main structure mode, related as follows [17]:

$$
\omega_{\mathrm{d}}=(1-\Delta) \omega_{n}
$$

Thus, the pth CBD frequency can be calculated by

$$
\omega_{p}=\left[(1-\Delta)+\left(p-\frac{m+1}{2}\right) \frac{\beta}{m-1}\right] \omega_{n} .
$$

In a thermal power plant structure, the mass of the coal scuttle can be determined first. Therefore, the objective function can be expressed as

$$
\min \sigma_{q_{n}}^{2}\left(\Delta, \beta, \xi_{\mathrm{d}}\right)
$$

In this paper, the optimization process is performed by numerical searching techniques using the MATLAB software package.

\subsection{Shaking Table Test}

2.2.1. Test Model. The current test model is simplified to provide the same basic structural dynamic characteristics as a coal-fired power plant. The test model is a four-story reinforced concrete frame structure with three coal buckets arranged at the third story. The structure is designed according to the Chinese Seismic Design Code [35]. The fortification intensity is 8 degrees $(0.2 \mathrm{~g})$, and the site characteristic period is $0.40 \mathrm{~s}$. The frame columns consist of $60 \times 105 \mathrm{~mm}$ sections, the transverse frame beams are $60 \times 60 \mathrm{~mm}$ sections, and the longitudinal frame beams are $60 \times 105 \mathrm{~mm}$ sections. All components of the power plant frame are constructed of C10 concrete, and the specific dimensions of the test model and the structural section reinforcement diagrams are provided in Figure 2. The test model is constructed to a $1: 30$ scale. Other 
similarity coefficients are determined according to similarity theory and are given in Table 1 .

An additional mass of $800 \mathrm{~kg}$ is included on each of the first to third stories, and an additional mass of $200 \mathrm{~kg}$ is added to the fourth story to replicate the presence of structure loading. These additional masses are uniformly arranged on each story. Including the mass of the structure, the total mass of the test model is $4122 \mathrm{~kg}$. Of this total mass, $420 \mathrm{~kg}$ on the third layer accounts for the mass of the coal buckets, or about $10.2 \%$ of the total weight of the structure.

2.2.2. CBD Parameters and Design. The dynamic characteristics of the structure were first obtained, and then the design parameters of the CBDs were determined according to the method detailed in Section 2.1. In order to facilitate the arrangement of equipment, the short-axis direction was selected as the loading direction in the test. Accordingly, the first, short-axis mode of the structure was chosen as the main control mode. First, an SAP2000 finite element analysis (FEA) model of the structure without CBDs was constructed, and the main dynamic characteristics of the structure were obtained by modal analysis. The main vibration control mode of the structure is shown in Figure 3. In the deformation of structure mode, the displacements where the coal buckets located are selected as the third-layer deformation.

According to the objective function and the dynamic characteristic parameters of the main control mode, the optimal design parameters of the CBDs were determined by numerical algorithm with the following results: $\beta_{\mathrm{opt}}=0.2$, $\Delta_{\text {opt }}=0.12$, and $\xi_{\text {dopt }}=0.05$. Figure 4 depicts the transfer function of the specified mode of the structure with and without CBDs, designed based on the above optimization procedure. The two curves intersect at points $P$ and $Q$, between which is the damping control operating range [36]. The frequency range of the operating range is 17.715$22.065 \mathrm{~Hz}$.

Under the optimal frequency coverage rate, $\beta_{\text {opt }}=0.2$, the spatial variation of the objective function value with the damping ratio $\xi_{\mathrm{d}}$ and frequency deviation $\Delta$ is shown in Figure 5. The deviation rate of the objective function value is less than $5 \%$ when the requirements of (17) are satisfied, which are taken as the design requirements such that

$$
\begin{gathered}
\Delta_{\text {opt }}-0.05<\Delta<\Delta_{\text {opt }}+0.05 \\
\xi_{\text {dopt }}-0.02<\xi_{\mathrm{d}}<\xi_{\text {dopt }}+0.02 .
\end{gathered}
$$

As shown in Figure 6, a CBD mainly consists of hanger rods, a steel coal bucket, elastic elements, and dampers. The hanger rods support the weight of the CBD and simultaneously provide oscillating stiffness. The CBD is horizontally connected to the frame columns by the elastic elements and dampers. The frequency of the CBD is adjusted by adjusting the stiffness of the elastic elements. When the CBD and the frame columns move relative to one another, the dampers provide enhanced damping force to limit the range of movement. The design requirements of the $\mathrm{CBD}$ damping ratio are met by adjusting the parameters of the damping elements.

The CBDs used in the shaking table test are of similar construction to the device illustrated in Figure 6. The elastic

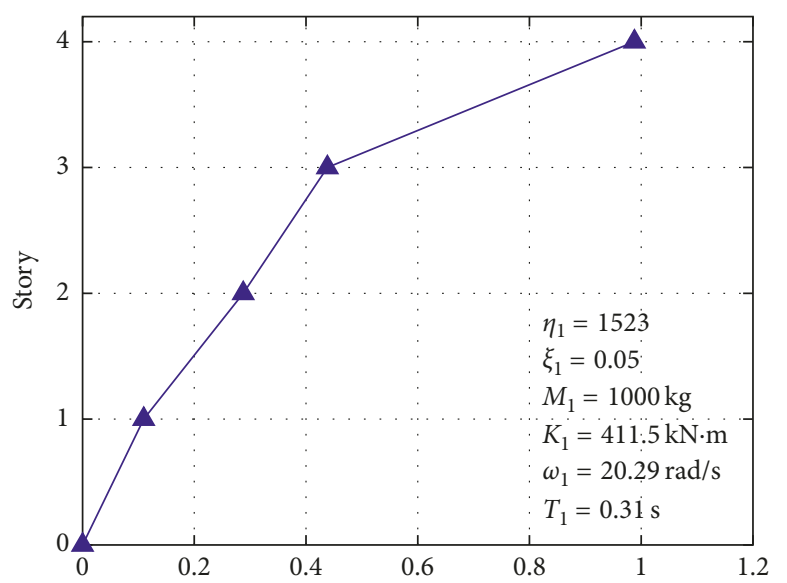

FIgURE 3: The main vibration control mode of the subject structure.

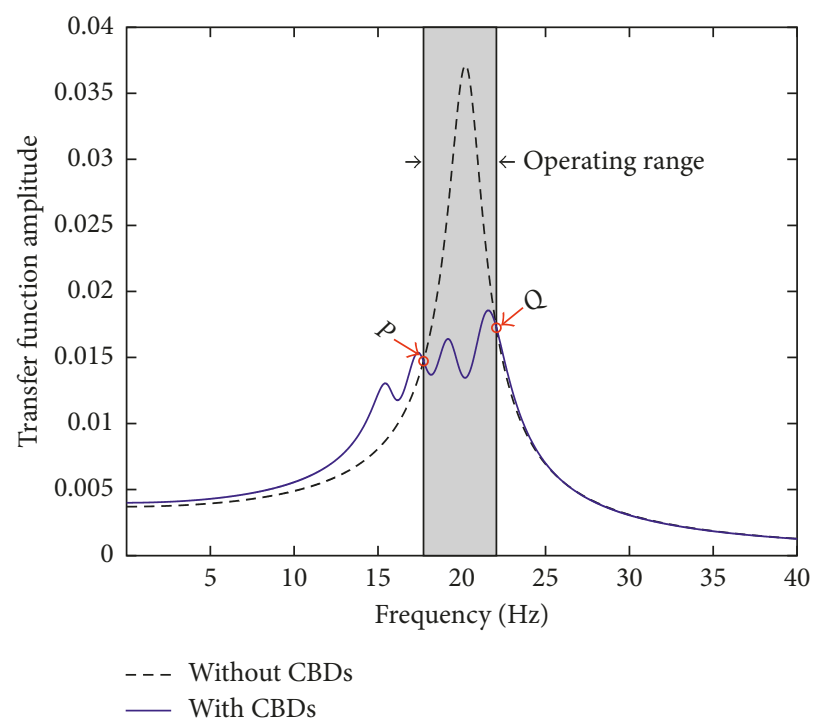

FIgUre 4: Transfer function of the structure with and without optimal CBDs.

element is a simply supported beam made of steel plate, as shown in Figure 7. The horizontal deformation stiffness of each CBD is provided by the swinging stiffness and deformation stiffness of this simply supported beam. Figure 7 (a) depicts a simplified mechanical model of the CBD system, yielding the following dynamic equations in the case of a small swing angle:

$$
\begin{aligned}
& M=-m g h \sin \theta-k h^{2} \sin \theta \cos \theta, \\
& M=J \beta,
\end{aligned}
$$

where $M$ is the moment of force, $m$ is the suspended mass, $g$ is the gravitational acceleration, $h$ is the height of suspension, $\theta$ is the swing angle, $k=48 E I / l^{3}$ is the elastic deformation stiffness of the simply supported beam, $E$ and $I$ are Young's modulus and section moment of inertia, respectively, $J=m h^{2}$ is the moment of inertia of a pendulum, and $\beta=d^{2} \theta / d t^{2}$ is the angular acceleration of the CBD. The simplified version of (19) can then be written as follows: 


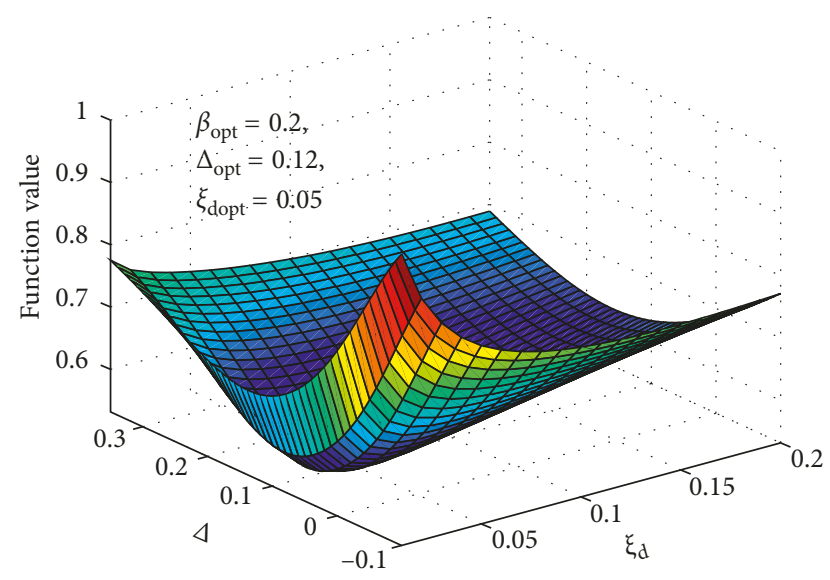

(a)

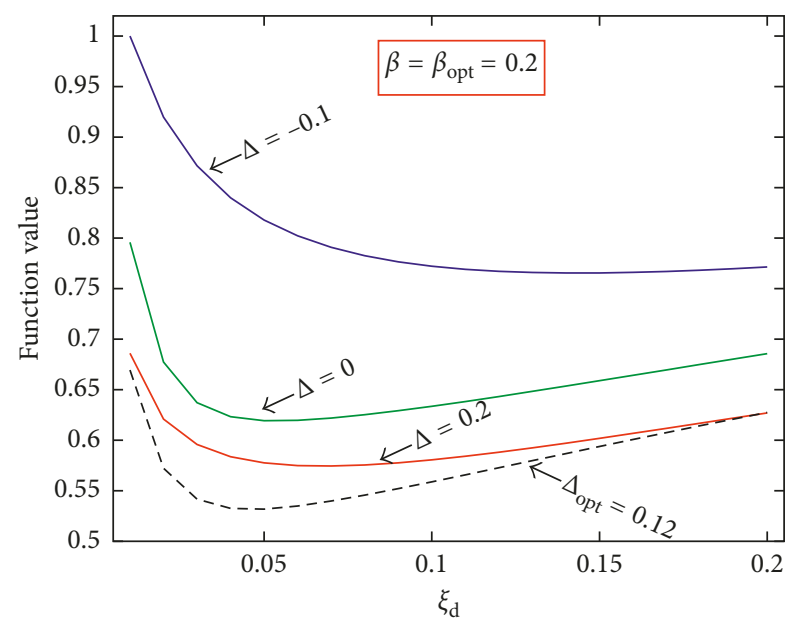

(b)

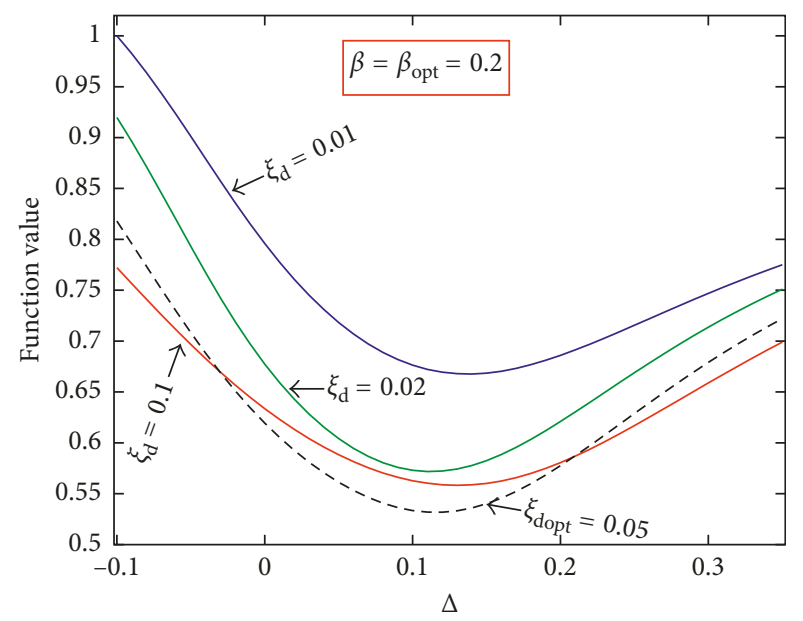

(c)

FIGURE 5: Relationship between objective function and different frequency deviation and damping ratio values under conditions of optimal coverage rate. Relationship between objective function and different values of (a) $\Delta$ and $\xi_{\mathrm{d}}$, (b) $\xi_{\mathrm{d}}$, and (c) $\Delta$.

$$
\frac{d^{2} \theta}{d t^{2}}+\frac{g}{h} \sin \theta+\frac{k}{m} \sin \theta \cos \theta=0 .
$$

And when the swing angle is small, the result is

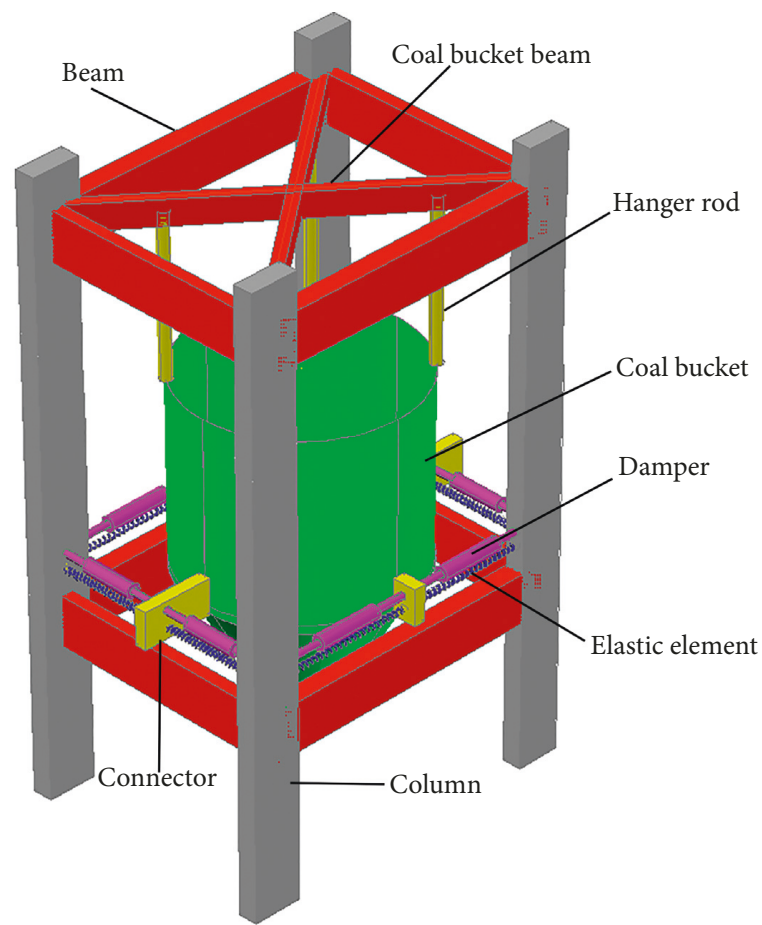

FIGURE 6: Schematic diagram of a coal bucket damper.

$$
\omega=\sqrt{\left(\frac{g}{h}+\frac{k}{m}\right)} .
$$

The detailed construction of the CBDs used in the shaking table test is shown in Figure 7(b). The coal bucket is hoisted to its structural level and connected to the midspan of the steel plate. The simply supported beam constraints are provided by special connectors. The upper left corner of Figure 7(b) shows these connectors, which consist of fixed holes and slotted holes. One end of the steel plate is connected by rivets through the fixed holes, providing a pinned connection, and the other end of the steel plate is connected by rivets through slotted holes, providing a roller connection. All connectors are fixed to the bottom of the frame column. In the shaking table test, three CBDs were arranged in the test model as shown in Figure $7(\mathrm{c})$. According to the design requirements dictated by the frequency ratio, the frequencies of the CBDs were determined, and then the deformation stiffness of the simply supported beam, calculated using (23), was determined. The stiffness requirement was met by changing the section size of the steel plate, which is shown in Figure 7(b):

$$
k=m\left(\lambda^{2} \omega^{2}-\frac{g}{h}\right) \text {. }
$$

The vibration characteristics of the CBDs were obtained through a manual excitation test. At a given initial vibration, the resulting free vibration attenuations of the three CBDs are as shown in Figure 8. The optimal and identified parameters of the three CBDs are shown in Table 2. The frequency ratio intervals between the three CBDs are somewhat different from the theoretical assumption, but the frequency coverage is basically consistent with the optimal design requirements. Notably, the vibration amplitude of the CBDs will affect the 


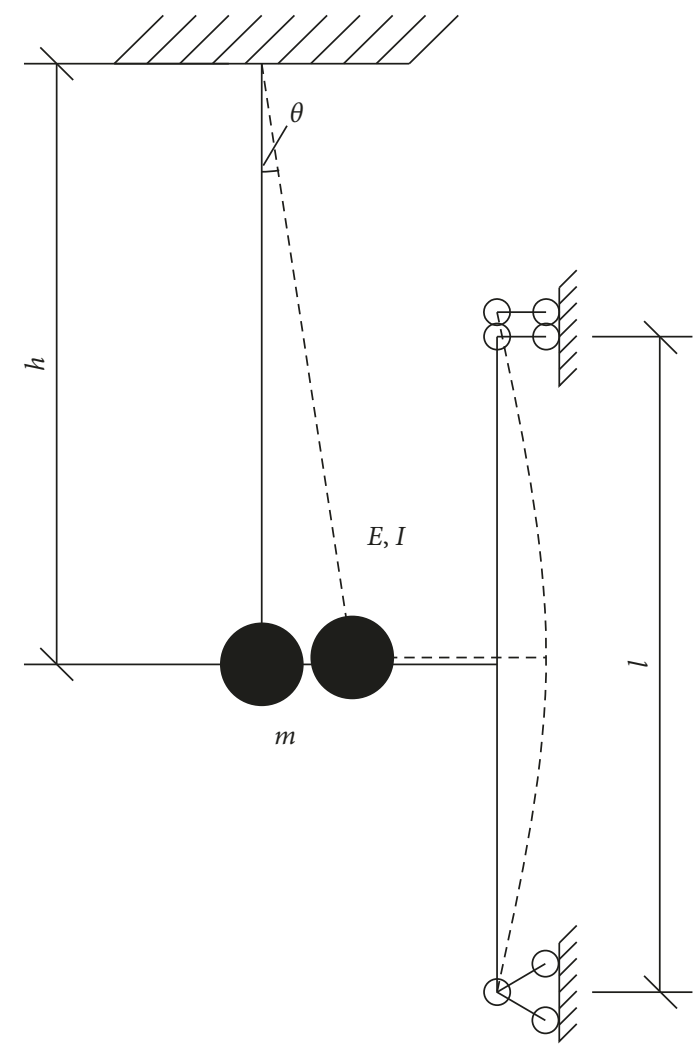

(a)

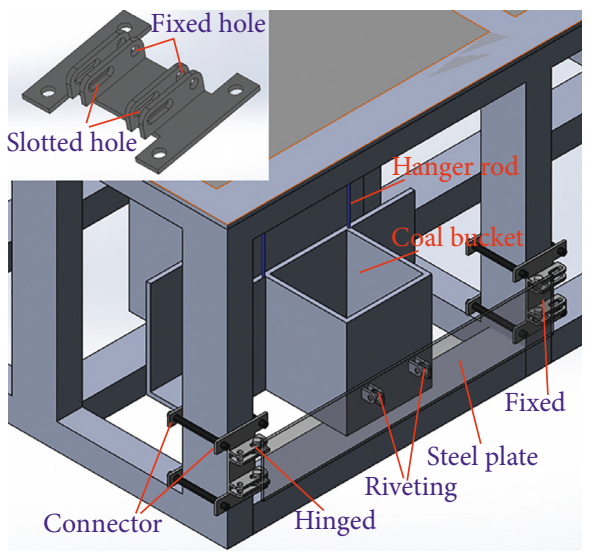

(b)

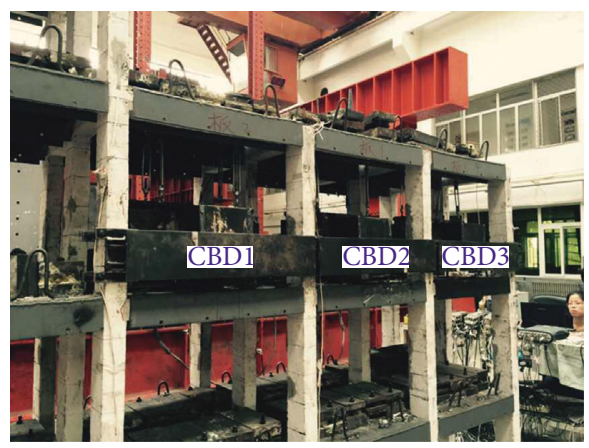

(c)

FIgURE 7: Coal bucket dampers used in the shaking table test model. (a) Simplified mechanical model of a CBD. (b) Detailed structural drawing of a CBD. (c) Layout of CBDs in test model.

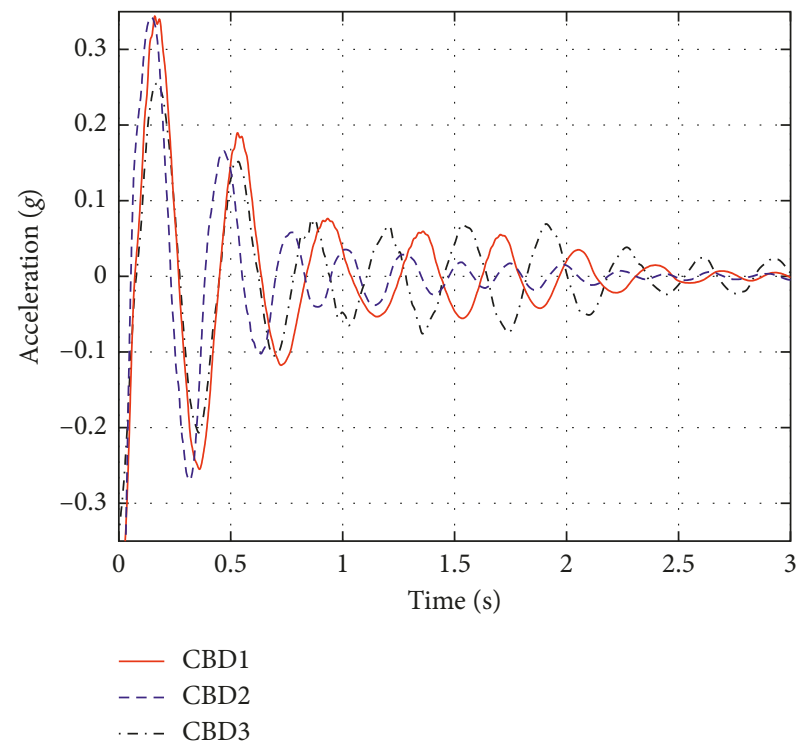

Figure 8: Free vibration attenuation curve for CBD1-3.

TABLe 2: Parameters of the three coal bucket dampers.

\begin{tabular}{lcccccc}
\hline \multirow{2}{*}{ CBD } & \multicolumn{2}{c}{ Mass (kg) } & \multicolumn{2}{c}{ Frequency (Hz) } & \multicolumn{2}{c}{ Damping ratio } \\
& Optimal & Identified & Optimal & Identified & Optimal & Identified \\
\hline 1 & 140 & 140 & 15.83 & 18.02 & 0.05 & 0.066 \\
2 & 140 & 140 & 19.88 & 20.35 & 0.05 & 0.076 \\
3 & 140 & 140 & 17.86 & 18.34 & 0.05 & 0.05 \\
Mean & 140 & 140 & 17.86 & 18.90 & 0.05 & 0.064 \\
\hline
\end{tabular}

A: acceleration sensor

$\mathrm{U}$ : displacement sensor
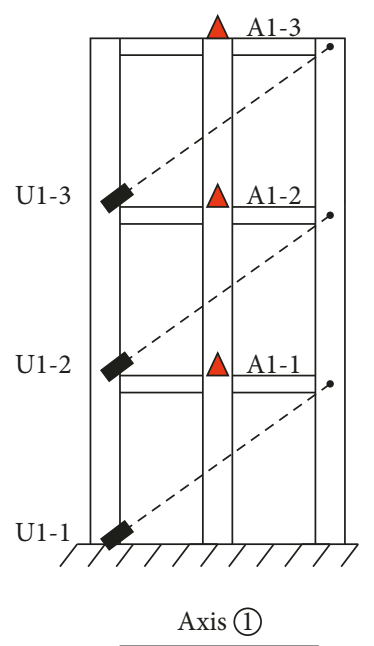

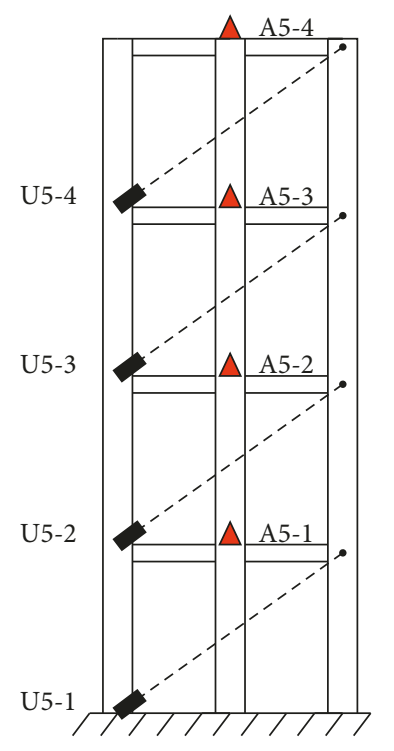

Axis (5)
Figure 9: Sensor placement.

damping ratio of the CBDs. Generally, the greater the vibration amplitude, the bigger the damping ratio. Because the damping ratio of the CBDs is maintained between 0.05 and 

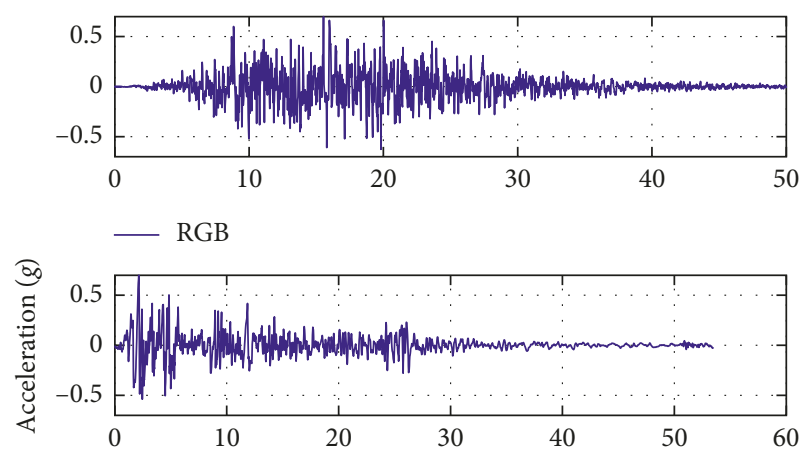

El Centro

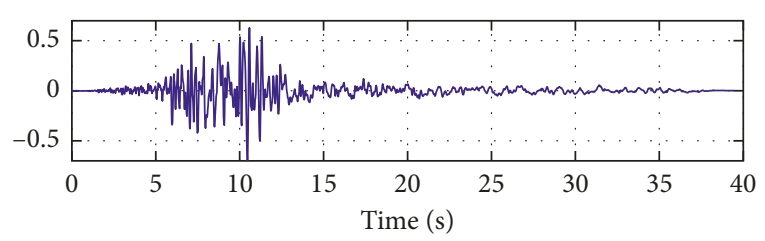

- Impvall

(a)

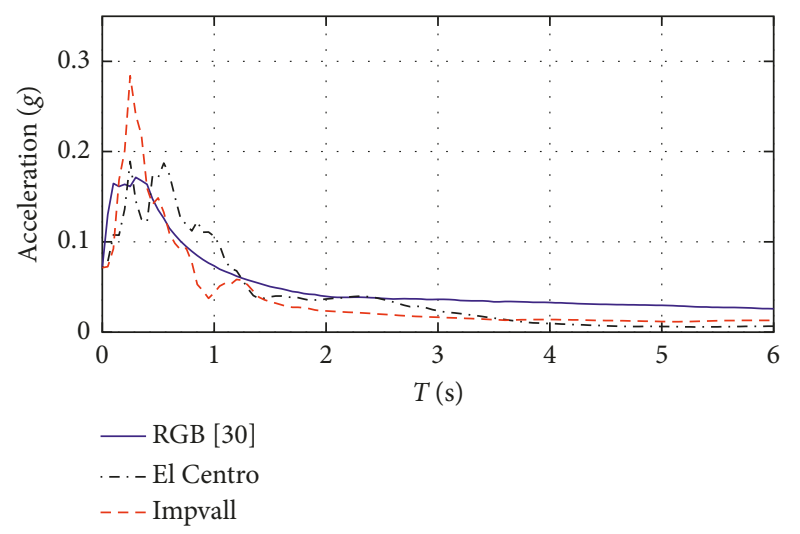

(b)

Figure 10: (a) Time history of seismic acceleration. (b) Response spectrum of seismic acceleration.

0.076 , the overall parameters can be considered to meet the optimal design requirements. As a whole, the experiment parameters meet the requirements of the target calculation.

2.2.3. Sensor Placement and Load Cases. Figure 9 depicts the position, orientation, and type of sensors used in the shaking table tests. The acceleration sensors (prefixes A1 and A5), which were used to measure the absolute acceleration at each story, were arranged along Axis (1) and Axis (5) of the structure. A single additional acceleration sensor was located on Axis (4) at the midpoint of the fourth story. Displacement sensors (prefixes U1 and U5) were arranged between the stories to measure the relative displacement between the stories of the test model. Three additional displacement sensors were located between the CBDs and the test model to measure the relative displacement between them.

The testing was conducted using the seismic simulation shaking table system of the Beijing Key Lab of Earthquake
TABLE 3: Test conditions.

\begin{tabular}{lccccc}
\hline Number & Code & CBDs & Intensity & $\begin{array}{c}\text { Earthquake } \\
\text { wave }\end{array}$ & $\begin{array}{c}\text { Peak } \\
(\mathrm{g})\end{array}$ \\
\hline 1 & W1 & No & - & White noise & 0.05 \\
2 & FE & No & Frequent & El Centro & 0.245 \\
3 & FI & No & earthquake & RGB & 0.245 \\
4 & FR & No & & 0.245 \\
5 & FE-T & Yes & Frequent & El Centro & 0.245 \\
6 & FI-T & Yes & earthquake & Impvall & 0.245 \\
7 & FR-T & Yes & & RGB & 0.245 \\
8 & W2 & Yes & - & White noise & 0.05 \\
9 & ME & No & Moderate & El Centro & 0.7 \\
10 & MI & No & earthquake & Impvall & 0.7 \\
11 & MR & No & & RGB & 0.7 \\
12 & W3 & No & - & White noise & 0.05 \\
13 & ME-T & Yes & Moderate & El Centro & 0.7 \\
14 & MI-T & Yes & earthquake & Impvall & 0.7 \\
15 & MR-T & Yes & & RGB & 0.7 \\
16 & W4 & Yes & - & White noise & 0.05 \\
17 & RR-T & Yes & Rare earthquake & RGB & 1.4 \\
18 & W5 & Yes & - & White noise & 0.05 \\
\hline
\end{tabular}

Engineering and Structural Retrofit at the Beijing University of Technology. The main parameters of this platform were as follows: the shaking table size was $3 \times 3 \mathrm{~m}$, the maximum load was 10 tons, the maximum stroke was $\pm 0.127 \mathrm{~m}$, the maximum speed was $0.6 \mathrm{~m} / \mathrm{s}$, the maximum acceleration was $2.0 \mathrm{~g}$, and the work frequency was $0.4-50 \mathrm{~Hz}$. When the test model was loaded, the seismic excitation was applied along the short axis of the structure. Ground motions, consisting of two actual strong earthquake records (El Centro and Impvall) and one artificial earthquake record (RGB), were selected in accordance with the Chinese Seismic Design Code [35]. The time history and response spectrum curves of these three seismic waves are shown in Figure 10. The time history curves clearly illustrate that the impulse characteristics of Impvall seismic wave are more distinct than those of the El Centro and RGB waves. Furthermore, the action time of the RGB wave at a high amplitude is as long as 20 s. Finally, these seismic waves must be adjusted according to the acceleration similarity coefficient provided in Table 1 .

The main research objective of these tests was to evaluate the structural vibration reduction effectiveness of the CBDs. Through testing, the seismic response of the original structure and the structure equipped with CBDs under the effects of a frequent-intensity earthquake $(0.245 \mathrm{~g})$ and a moderate-intensity earthquake $(0.7 \mathrm{~g})$ were measured and compared. Finally, a rare-intensity earthquake test condition was applied to the $\mathrm{CBD}$-equipped structure to investigate the control effect of CBDs under the action of a large earthquake. The specific test conditions are detailed in Table 3. Note that the same model was used in both the original and CBD-equipped tests, and the contribution of the CBDs was controlled by fixing or relaxing the coal bucket connections.

\section{Experimental Results and Numerical Simulation Analysis}

3.1. Shaking Table Test Results. The results of the shaking table test mainly include the frequency scanning results, 


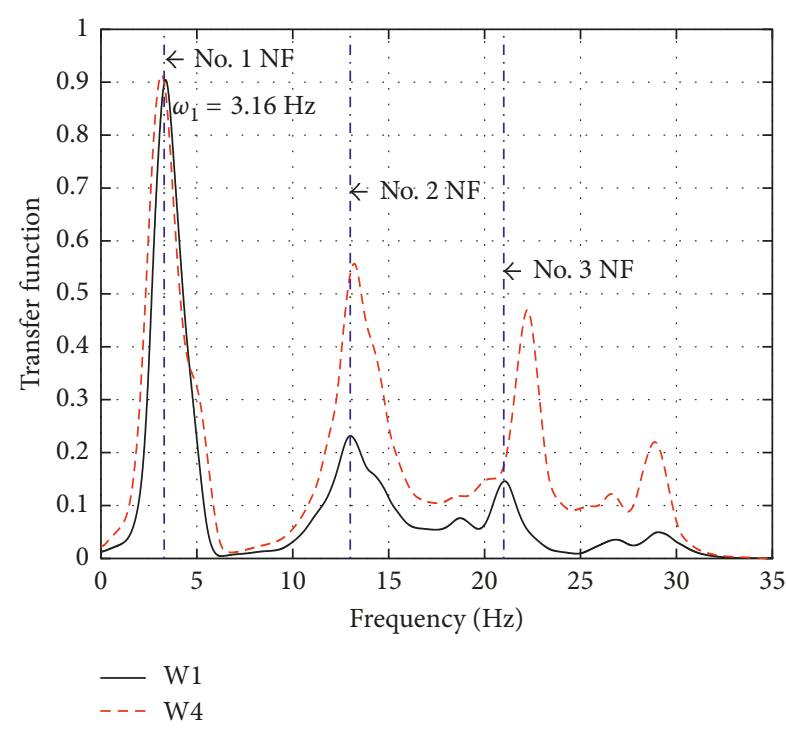

FIgURE 11: Transfer function of model under white-noise input. $\mathrm{W} 1$ and $\mathrm{W} 4$ are the test conditions given in Table 2, and NF is the natural frequency of the structure determined by SAP2000 model.

interstory displacement response results, and absolute acceleration response results for each story. The reduction effects of the CBDs were calculated using the peak value and the root mean square (RMS) of the displacement and acceleration, respectively.

3.1.1. Model Test Results. Figure 11 shows the acceleration transfer function of the top story of the test structure at the first and the fourth white-noise excitation conditions. The firstorder frequency of the test structure was $3.16 \mathrm{~Hz}$, and the error between the test result and the numerical simulation result was $2.2 \%$. This low error indicates that the design parameters of the test CBDs still meet the optimal design requirements. Furthermore, the modal test results show that prior to the rare earthquake condition, the first and second natural frequencies of the structure changed very little, indicating that under frequent- and moderate-intensity earthquake conditions, the design frequency of the CBDs does not significantly deviate.

3.1.2. Displacement Reduction Effect. The average peak and RMS interstory drift values for the three sets of frequent earthquake conditions evaluated were $11.4 \%$ and $17.7 \%$, respectively. Under moderate earthquake conditions, the peak and RMS of interstory drift increased by $14.0 \%$ and $23.0 \%$, respectively. The peak and average RMS displacement reduction rates of each story under frequent and moderate earthquake conditions are seen in Figure 12, in which the following can be observed:

(1) The RMS reduction rates of interstory drift are obviously better than the peak reduction rate, and the RMS reduction rates are more stable. However, the peak inter-story drift of the top story shows no obvious reduction effect under the application of the Impvall seismic excitation. The peak and RMS reduction rates of inter-story drift are optimal under the El Centro seismic excitation.
(2) The RMS reduction rates are not consistent with the peak reduction rates. The peak reduction rate under the RGB seismic excitation is better than under the Impvall seismic excitation, but its RMS reduction rates are worse than those under the Impvall seismic excitation.

(3) The peak reduction rates have a certain downward trend in the story above the CBDs, while the RMS reduction rates have a certain upward trend in the same region. This phenomenon is obvious under the action of moderate-intensity seismic excitation.

Figures 13 and 14 show the interstory drift of the second and fourth stories of the subject structure for both test cases (with and without CBDs) when subjected to frequent- and moderate-intensity earthquakes, respectively. It can be seen that the displacement shock absorption of the structure is similar under all tested conditions. At the beginning of each earthquake, the displacement of the structures with and without CBDs is synchronous, but eventually the vibration amplitude of the CBD-equipped structure indicates obvious dampening, suggesting that the CBDs provide obvious hysteresis characteristics, much like traditional passive TMDs. The displacement shock absorption of the structure under the Impvall seismic excitation is shown in Figures 13(b) and 14(b). It can be seen that the structural displacement reaches a peak after a short time, and that the CBDs have not yet played a role in reducing it, leading to a very small peak reduction rate. However, in the later stages of the applied earthquakes, it is obvious that the vibration of the structure with CBDs rapidly decays until it no longer vibrates. This illustrates that the RMS reduction rates of interstory drift are still ideal. Among the three sets of seismic wave conditions, the RMS reduction rate of the RGB excitation is the smallest, as shown in Figures 13(c) and 14(c).

There are clearly some similarities and differences between the displacement shock absorption of the CBD-equipped structure under frequent and moderate earthquake conditions. The main similarity is the action hysteresis, that is, the CBDs begin to function after a certain displacement occurs in the structure, following which the displacement decay rate begins to grow, demonstrating that the equivalent damping ratio of the structure has increased, achieving the desired vibration control effect.

The main difference between structure responses under frequent and moderate earthquake conditions is that the reduction rates of displacement under a frequent-intensity earthquake are better than those under a moderate-intensity earthquake. The reasons for this behavior are complex: due to the increase in the peak value of the input ground motion, the vibration amplitude of the structure becomes larger and the duration over which the CBDs act becomes longer, and the increase in the vibration amplitude of the CBDs causes some of the performance characteristics of the CBDs to change. Generally, the larger the vibration amplitude of the CBDs, the better their energy dissipation capability, or, in other words, the larger their damping ratio. Indeed, some existing research indicates that increasing the damping ratio of a TMD can increase the displacement reduction rate of the structure [27]. 


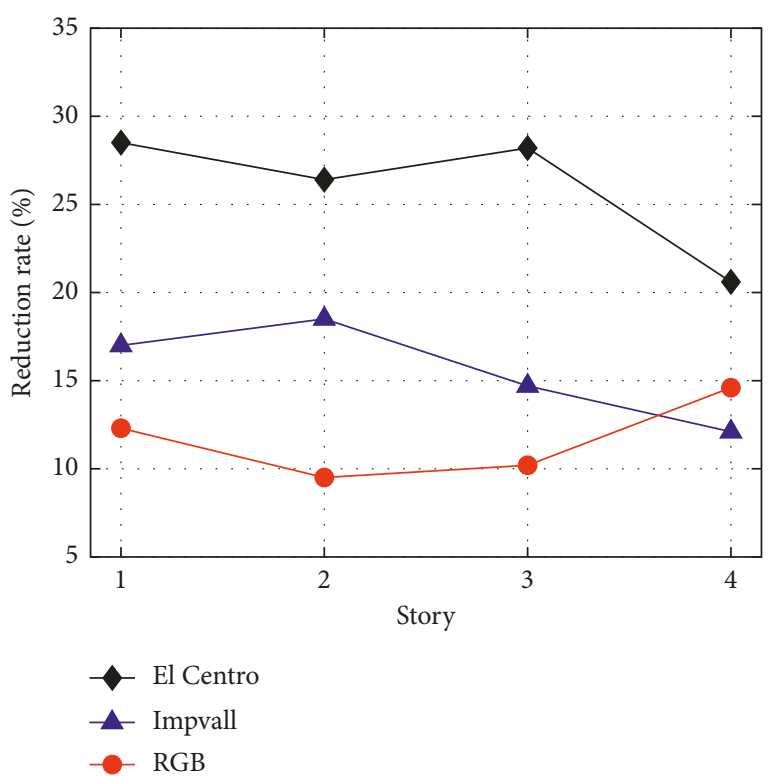

(a)

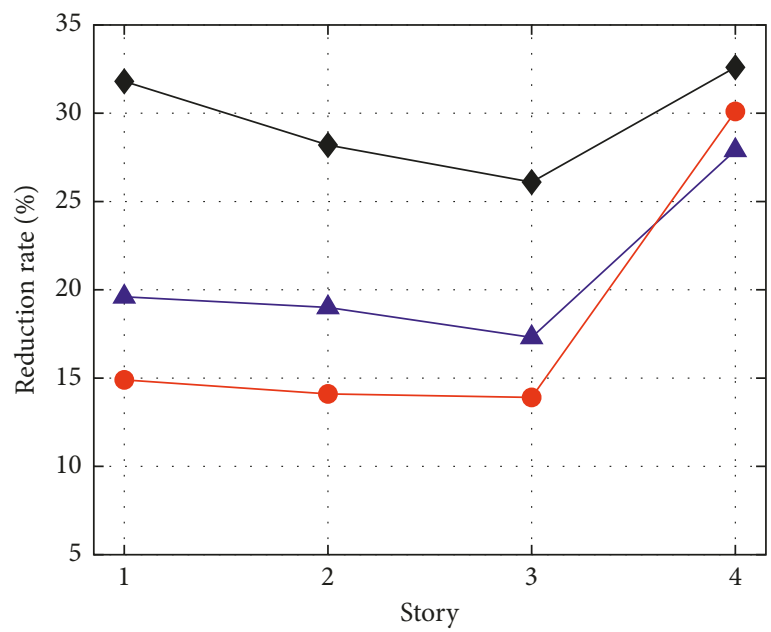

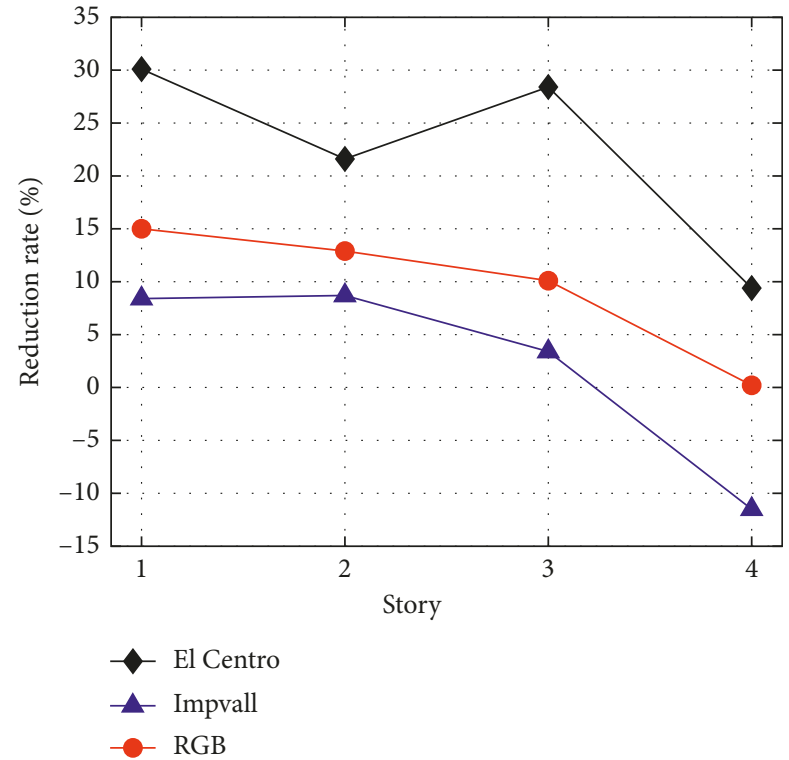

(b)

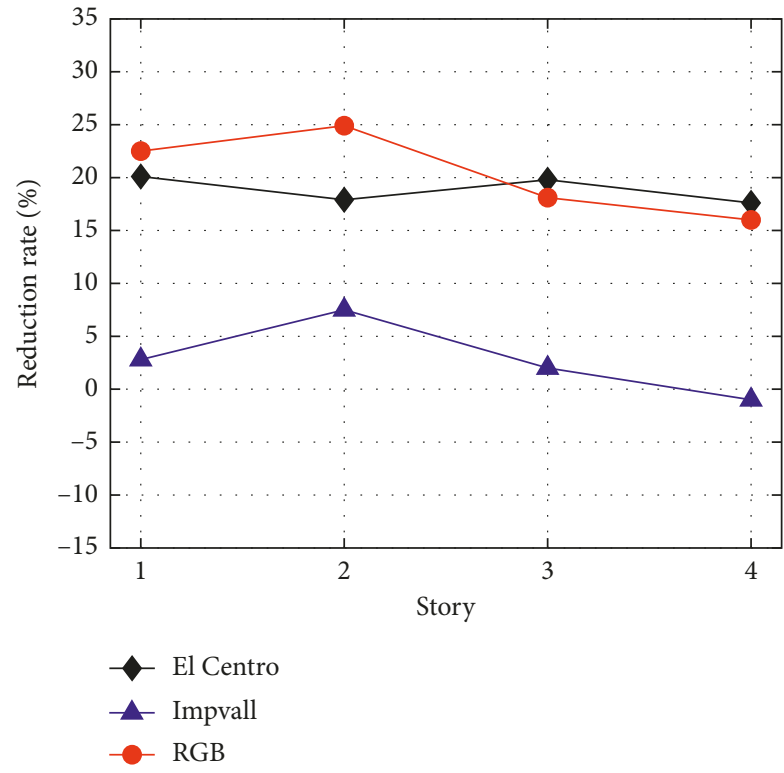

(d)

FIGURE 12: Displacement reduction rates under applied seismic conditions. RMS reduction rate of displacement under (a) frequentintensity earthquake conditions and (c) moderate-intensity earthquake conditions. Peak reduction rate of displacement under (b) frequentintensity earthquake conditions and (d) moderate-intensity earthquake conditions.

Overall, the displacement response of the CBD-equipped structure is obviously superior to that of the traditional structure, indicating that $\mathrm{CBD}$ technology can increase the damping ratio of the structure and exert a superior control effect on the displacement response of the structure.

3.1.3. Acceleration Reduction Effect. The acceleration responses of the CBD-equipped structure are shown in Figure 15, from which it can be inferred that the CBDs have no obvious control effect on the peak and RMS acceleration response of the first and second stories, where the phenomenon of aggravating response even appears. However, the acceleration responses of the $3 \mathrm{rd}$ and 4 th stories show promising reduction rates. Under frequent-intensity earthquake conditions, the average values of the peak and RMS acceleration reduction rates for all stories are $-3.4 \%$ and $3.3 \%$, respectively, and under moderate-intensity earthquake conditions, the average values increase to $1.2 \%$ and $8.8 \%$, respectively, indicating that as the peak of the input ground motion increases, the acceleration reduction rate increases, which is consistent with the reduction rates of interstory drift. Overall, the control effect of the CBDs on the acceleration response of the story in 

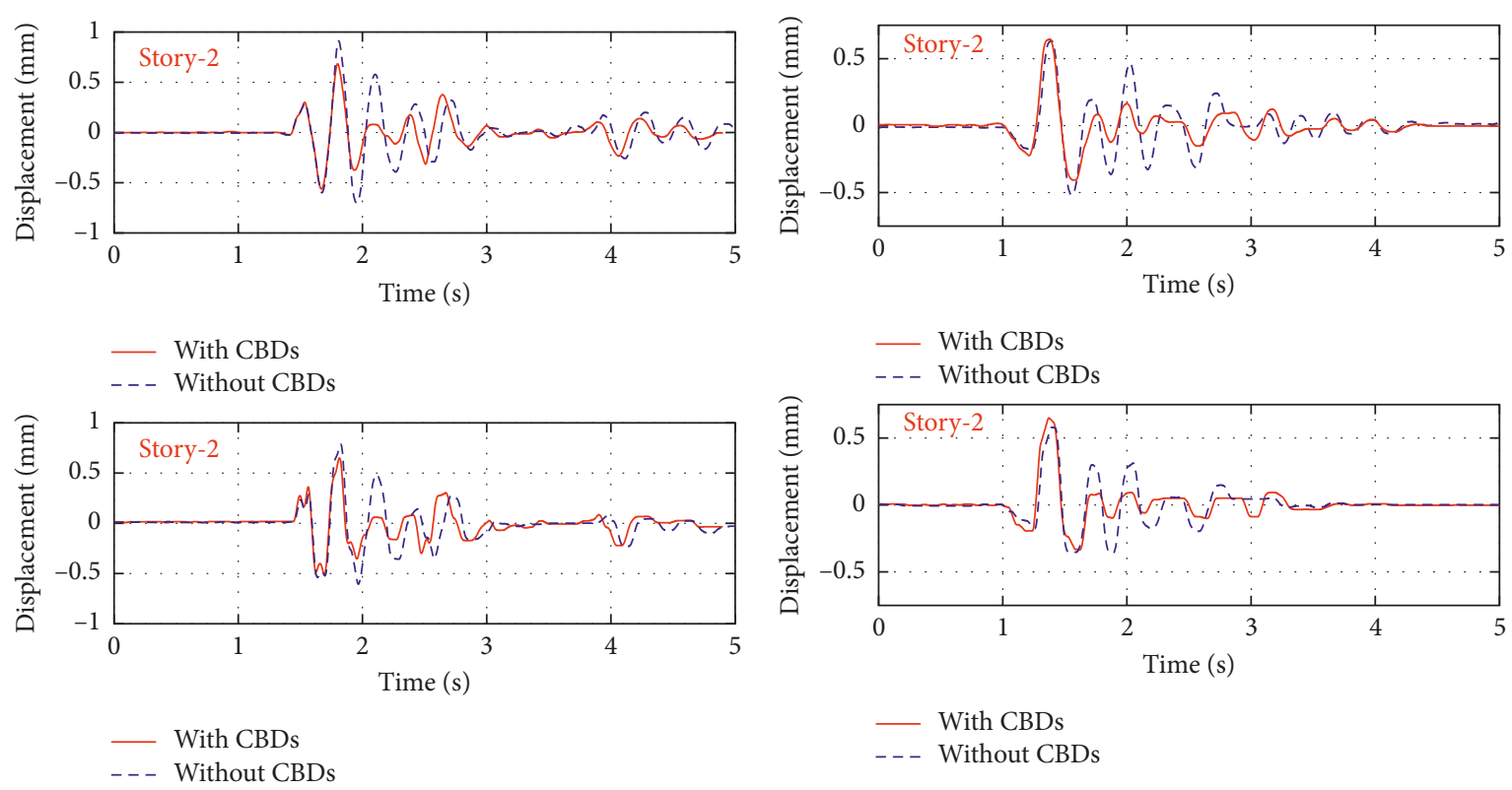

(a)

(b)
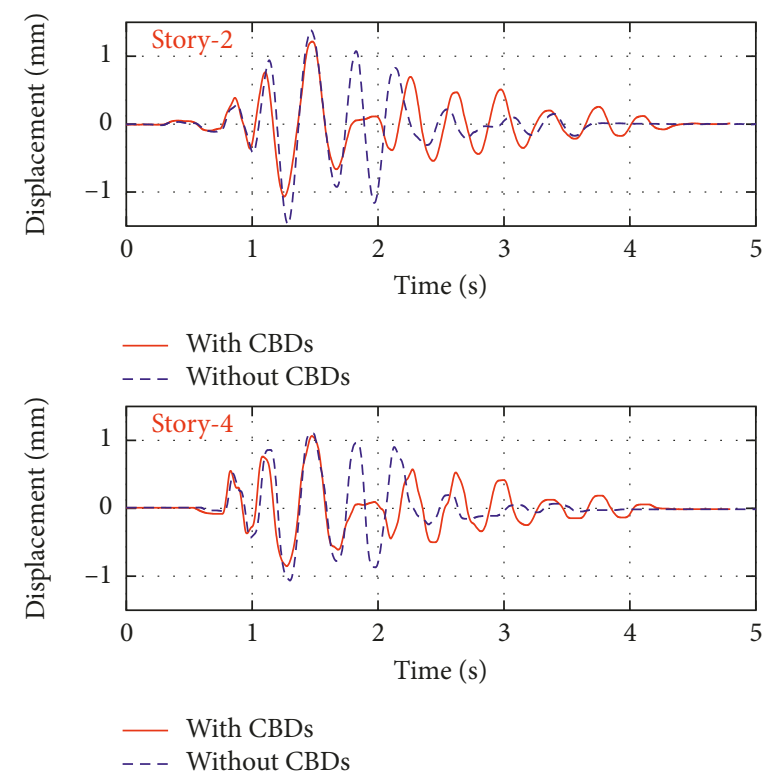

(c)

FIGURE 13: Time-history comparison of interstory displacements under frequent-intensity earthquakes: (a) El Centro, (b) Impvall, and (c) RGB.

which they are located and that above is improved, but the stories below the CBDs still exhibit behavior that is less than ideal.

3.2. FEA Results and Analysis. In the shaking table test, the CBD-equipped structure exhibited promising damping effects in terms of displacement response. To evaluate behaviors not immediately obvious or obtainable in shaking table tests, the seismic stability of the CBD-equipped structure was also analyzed by numerical simulation. Shaking Table Test Results. A finite element analysis (FEA) model of the test structure with and without CBDs was constructed using the SAP2000 software package [37] and is shown in Figure 16. The elastic constitutive relation was used for the materials in the FEA model. In the FEA model of the CBD-equipped test structure, the mass of the coal buckets was simulated by assigning mass attributes to the nodes. The LINK element was used to connect the node and the structure, and the stiffness and damping properties of this element were adjusted to simulate the dynamic characteristics of the CBDs.

Based on the time-history analysis method, the dynamic response of the structural FEA model with and without CBDs was analyzed and compared. The results of this numerical analysis were then compared with the test results. In the test 

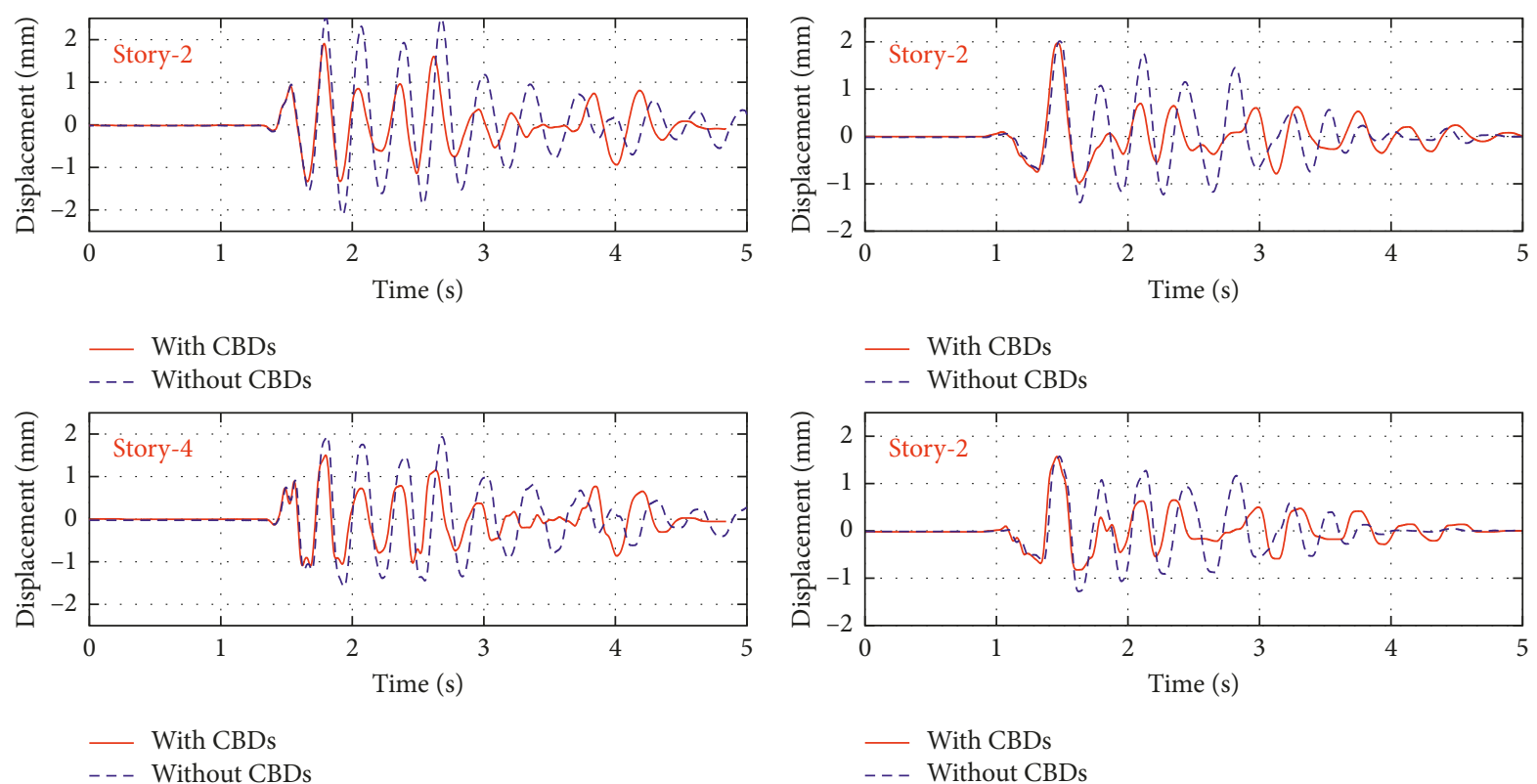

(a)

(b)
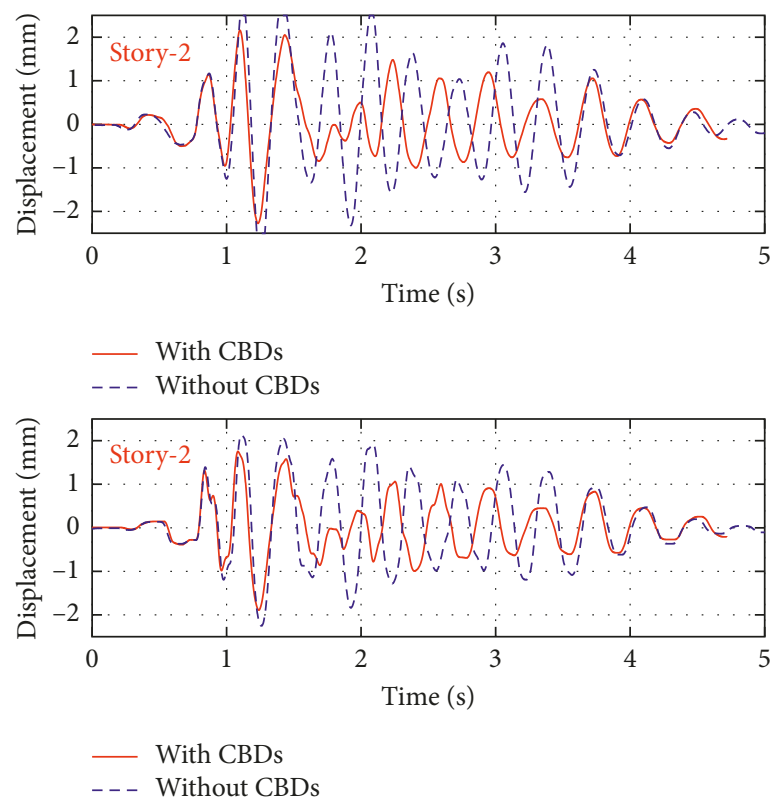

(c)

FIGURE 14: Time-history comparison of interstory displacements under moderate-intensity earthquakes: (a) El Centro, (b) Impvall, and (c) RGB.

process, the performance of both the structure and the CBDs was affected by the cumulative effect of multiple test conditions. However, the FEA model is an ideal model, and the results from each tested condition are independent and do not affect one another. Because of this, the FEA calculation results showed small error when compared to the test results. Figures 17(a) and 17(b) show the interstory drift control effect of the CBDs in the test model and the FEA model under the action of the El Centro and Impvall seismic excitations, respectively. Figure 17(c) shows a comparison of the relative displacements of CBD3 in the test model and the FEA model. As indicated in Figure 17(c), the relative displacements of the $\mathrm{CBDs}$ reflect interactive responses between the frame and CBDs, indicating that the damping components of the CBDs actively dissipate seismic energy.

It can be seen from these results that the overall response trend between the test model and the FEA model is consistent, and the indicated reduction effects of the CBDs are in good agreement.

\subsubsection{Influence of Seismic Wave Discreteness on Reduction} Rate. Previous studies have demonstrated that structures with tuned mass dampers are significantly affected by the randomness of ground motions, and that the seismic 


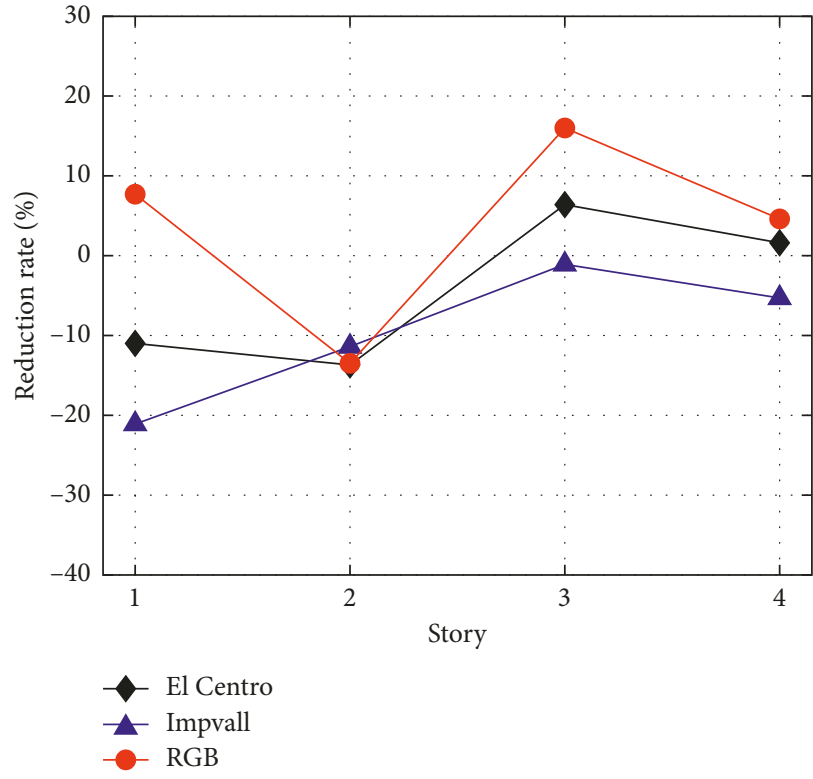

(a)

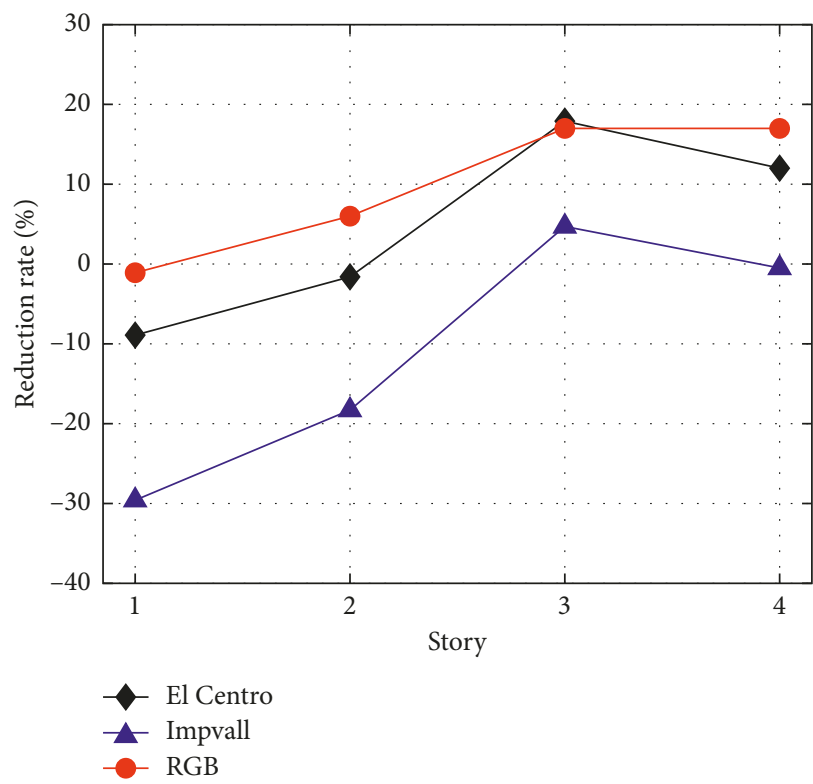

(c)

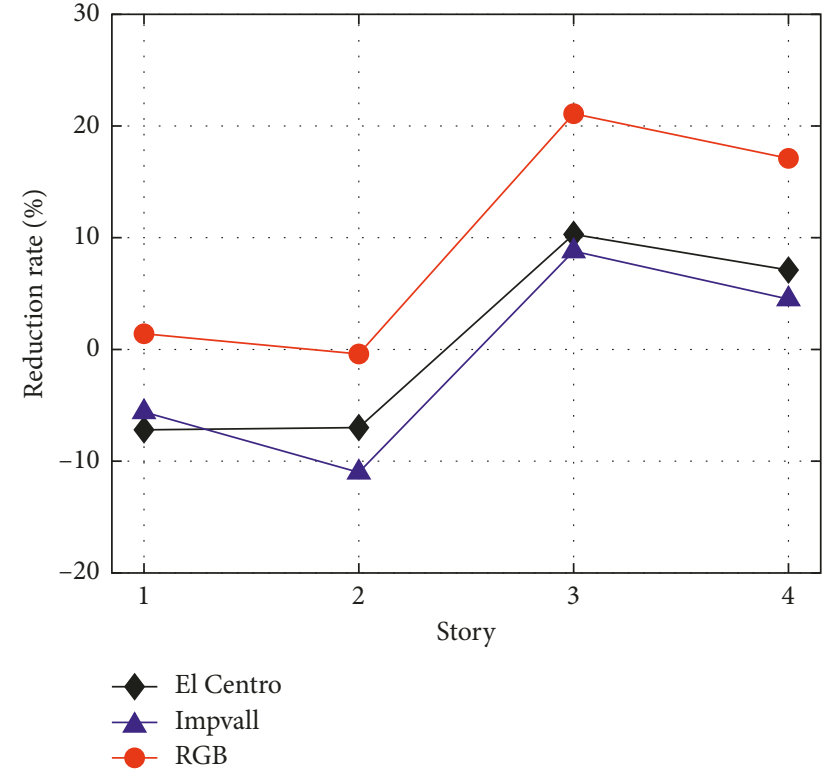

(b)

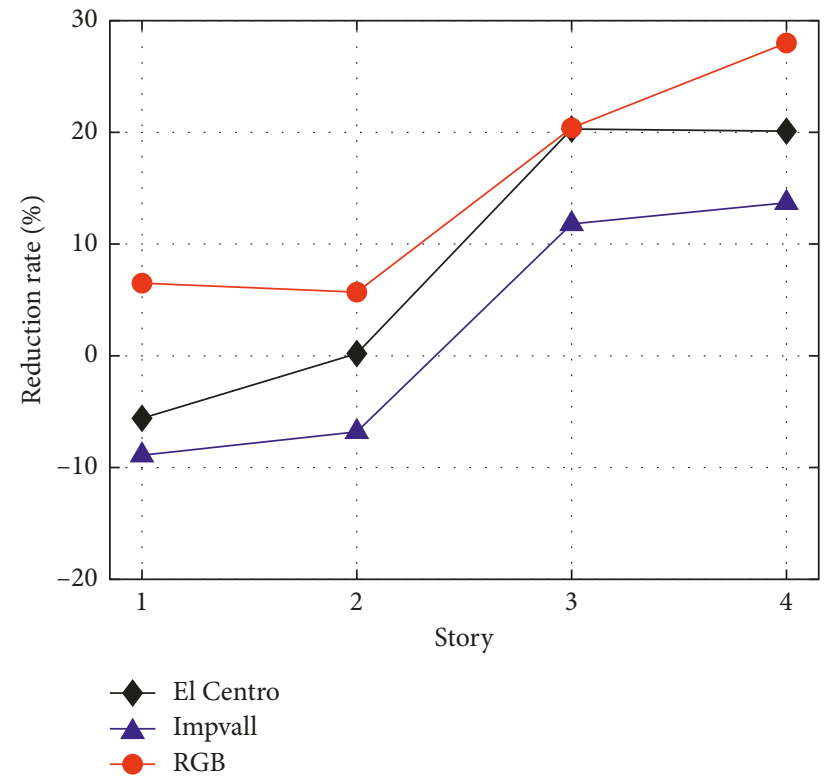

(d)

FIGURE 15: Acceleration reduction rates under frequent- and moderate-intensity earthquake conditions. Peak reduction rate of acceleration under (a) frequent-intensity earthquake conditions and (c) moderate-intensity earthquake conditions. RMS reduction rate of acceleration under (b) frequent-intensity earthquake conditions and (d) moderate-intensity earthquake conditions.

effectiveness of a TMD is highly dependent on frequency, in that it only operates efficiently under resonant conditions [36]. To determine the shock absorption reliability of the CBDs in the evaluated structure, 22 far-field ground motions and 28 near-field ground motions suggested by ATC-63 [38] were selected as input seismic waves. The three seismic excitations used in the shaking table test were also applied, making 53 seismic waves in total. The absolute acceleration response spectra of the 22 far-field seismic waves and the 28 near-field seismic waves are shown in Figures 18(a) and 18(b), respectively. The seismic waves were scaled for numerical analysis according to the time similarity coefficients provided in Table 1.

The randomness of seismic waves has a significant influence on the damping effect of a structure equipped with CBDs. Under the optimal design parameters, the structural displacement and acceleration damping under the 53 evaluated sets of seismic conditions are shown in Figures 19(a) and (b). The displacement RMS and the peak reduction rates were $17.2 \%$ and $9.6 \%$, respectively, and the acceleration RMS 


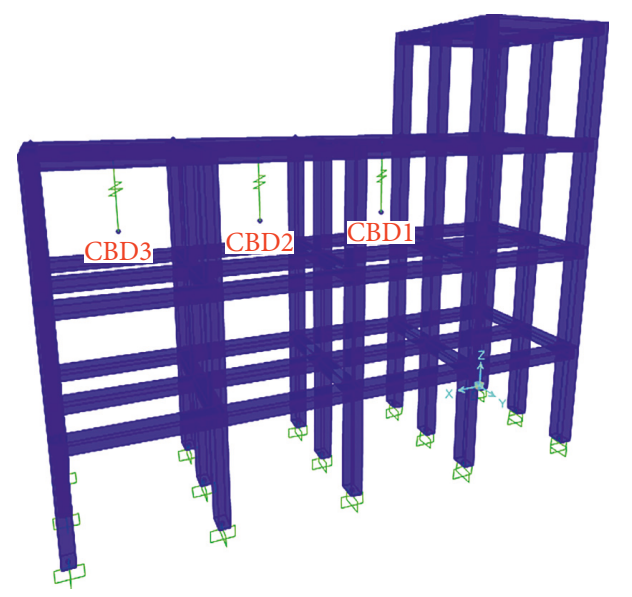

Figure 16: Finite element model of the subject structure.

and peak reduction rates were $2.1 \%$ and $-1.9 \%$, respectively. In addition, the following conclusions can be drawn from the analysis results:

(1) When using the CBDs at their optimal parameters, the displacement and acceleration reduction rates under each earthquake condition have a certain discreteness. For example, the RMS of the reduction rate and the peak value of displacement under the 23rd seismic wave were $40.0 \%$ and $28.3 \%$, respectively, while the RMS and peak value under the 38 th seismic wave increased by $7.7 \%$ and $6 \%$, respectively. Figure 20(a) depicts the Fourier amplitude spectrum of the 23rd seismic wave and the 38th seismic wave. It can clearly be observed that the components of the 23rd seismic wave are larger than those of the 38 th seismic wave in the operating range. Therefore, the performance of the CBDs is obviously excellent under the 23rd seismic wave, but not good under the 38th seismic wave, as expected in the frequency domain. Figures 20(b) and 20(c) show a comparison of interstory drift and seismic wave acceleration response spectra, respectively, between the $23 \mathrm{rd}$ condition and the 38 th condition. In the response spectrum of the 23rd seismic wave, the amplitude of the component corresponding to the structure control mode period is near the local maxima of the response spectrum. However, in the 38th seismic wave response spectrum, that amplitude is near the minimum of the response spectrum. This leads to a difference in the contribution of the control mode to the structural response. The higher the contribution of the main control mode, the better the control effect.

(2) According to the seismic wave response spectrum shown in Figure 18, the average amplitude of the response spectrum, corresponding to the structure control mode period, of the 28 near-field seismic waves is clearly greater than that of the 22 far-field seismic waves. The reductions under the near-field seismic waves are better than those under the far- field seismic waves, which are consistent with the seismic wave response spectrum results.

(3) Under the 53 different seismic waves, the qualities of the structural displacement reduction rate are different from those of the acceleration reduction rate. The largest and smallest displacement RMS reduction rates are under the 23rd and the 38th seismic wave conditions, respectively, while the largest and the smallest acceleration RMS reduction rates are under the 23rd and the 9th seismic wave conditions. Notably, the displacement control effect of the CBDs is obvious, while the acceleration control is less than ideal.

Overall, the control effect of the CBDs illustrates a certain discreteness. Although the CBDs are less useful outside of their resonant conditions, the structural response is small in this situation. Notably, the basic vibration frequency of a conventional coal-fired power plant structure is often located in a region with a larger Fourier amplitude. Because the CBDs provide efficient vibration control, this basic vibration behavior suggests that they can be successfully used in coalfired power plant structures to ensure seismic stability.

\subsubsection{Influence of Structural Period Change on Reduction} Rates. Under the combined influence of construction, lifecycle, and environmental factors associated with coalfired power plant structures, the dynamic characteristics of the existing structure will differ from those of the originally designed structure. Furthermore, when the structure is subjected to a strong earthquake, it will experience damage and a subsequent decrease in stiffness. This will lead to a deviation between the real structural response cycle and the designed structural response cycle, which will, in turn, influence the vibration control effect of the CBDs. To determine the influence of the structural period change on the reduction rate provided by the CBDs, the vibration reduction effect on structures with different periods, designed using initially optimized parameters, was analyzed. The structural period change was simulated by changing the elastic modulus parameters of the material in the model. Figures 21(a) and 21(b) show the displacement and acceleration reduction rates, respectively, of structures with different periods. It can be seen that when the ratio of the current structure period $(T)$ to the design structure period $\left(T_{1}\right)$ is within the range of $0.85-1.4$, the reduction effect is relatively stable, the displacement RMS reduction rate is maintained above $16 \%$, and the displacement peak reduction rate is above $9 \%$. When the structure period $(T)$ exceeds $1.4 T_{1}$, the control effect of the structure enters a period of significant decline, but the displacement RMS and the peak reduction rates are still maintained. Notably, the structural period change has little influence on the acceleration reduction rate. Overall, when the structure period deviates from the initial design period, or the structure is subjected to earthquakes of rare intensity, the presence of CBDs on a structure can continue to work to maintain a certain degree of seismic stability. 

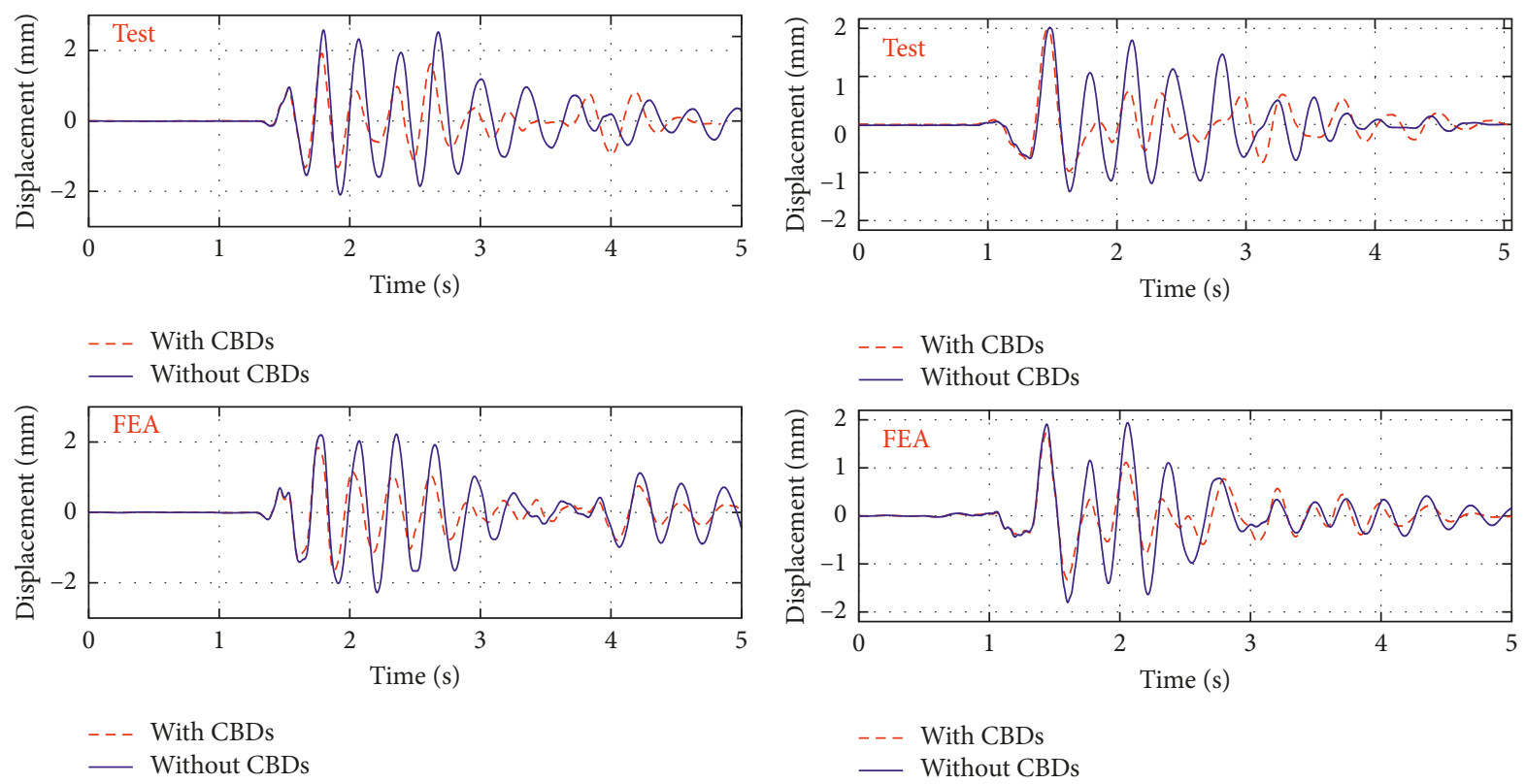

(a)

(b)
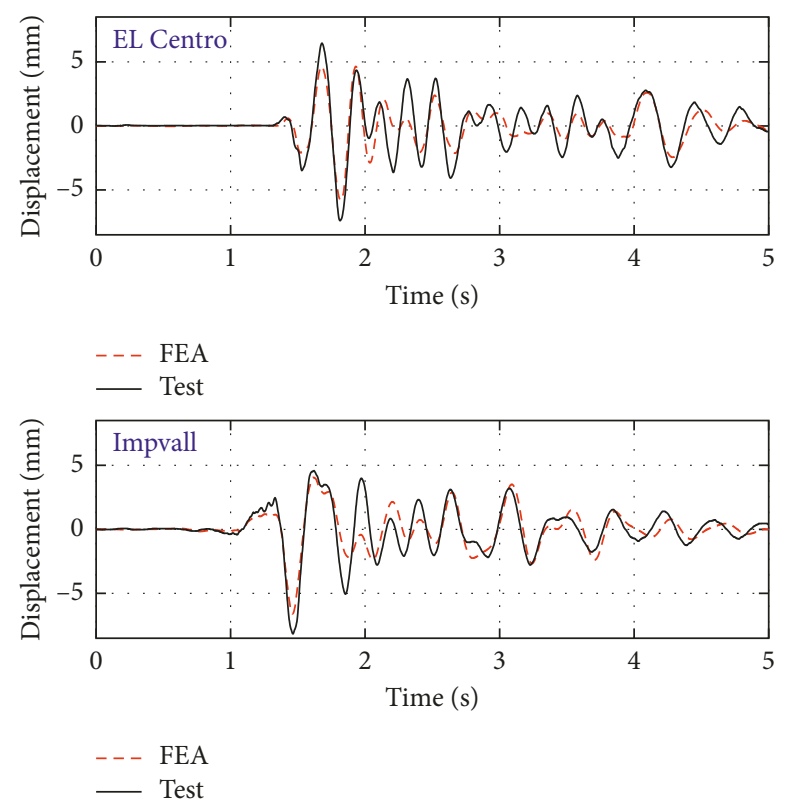

(c)

Figure 17: Comparison of responses between test and FEA models. Time-history response of story drift under (a) El Centro seismic excitation and (b) Impvall seismic excitation. (c) The displacement response of CBD3 under El Centro and Impvall seismic excitations.

\section{Conclusion}

Coal-fired power plants will continue occupy a significant place in the electricity generation market for the foreseeable future. However, many critical domestic and foreign coalfired power plants are prone to earthquakes. Considering the unique complexity of these plant structures, it is important to ensure their seismic safety. To this end, massive coal buckets can be designed to act as coal bucket dampers, turning the disadvantage of high mass into an advantage in damping seismic vibrations. In this paper, an optimized method for designing CBD parameters is established based on MTMD damping theory, and their vibration reduction effects and contributions to the seismic stability of a coalfired power plant structure are studied using both shaking table tests and finite element numerical simulations. The main conclusions are as follows: 


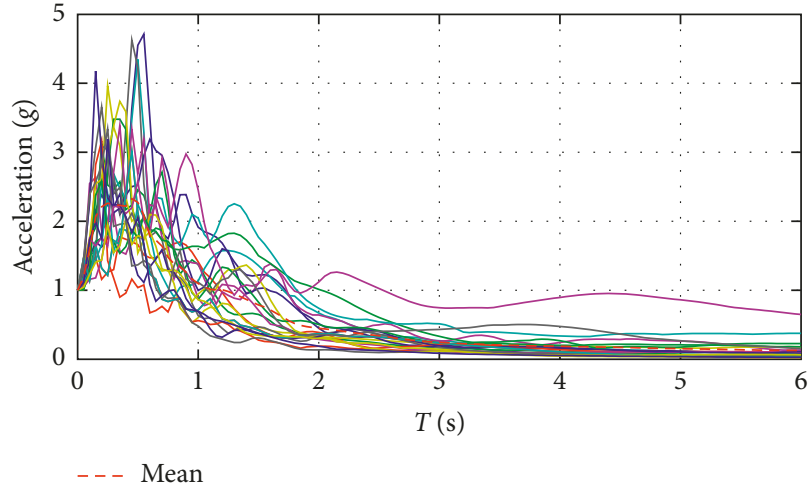

(a)

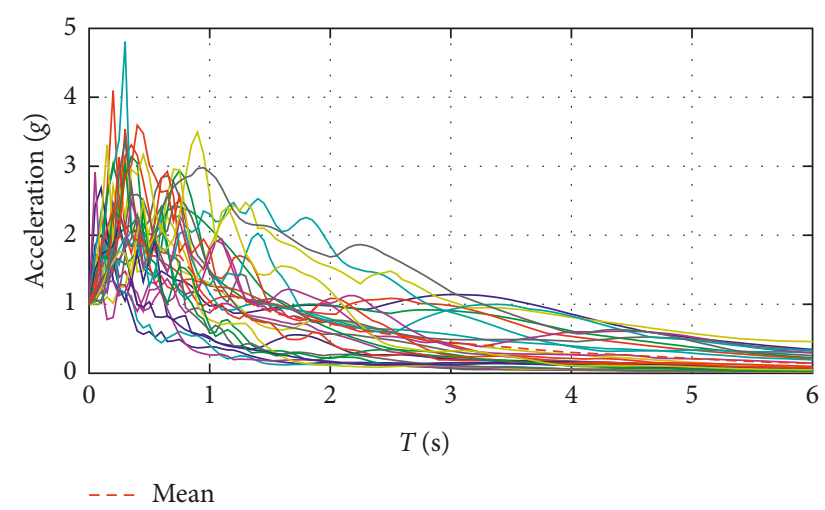

(b)

Figure 18: (a) Far-field and (b) near-field seismic wave response spectra.

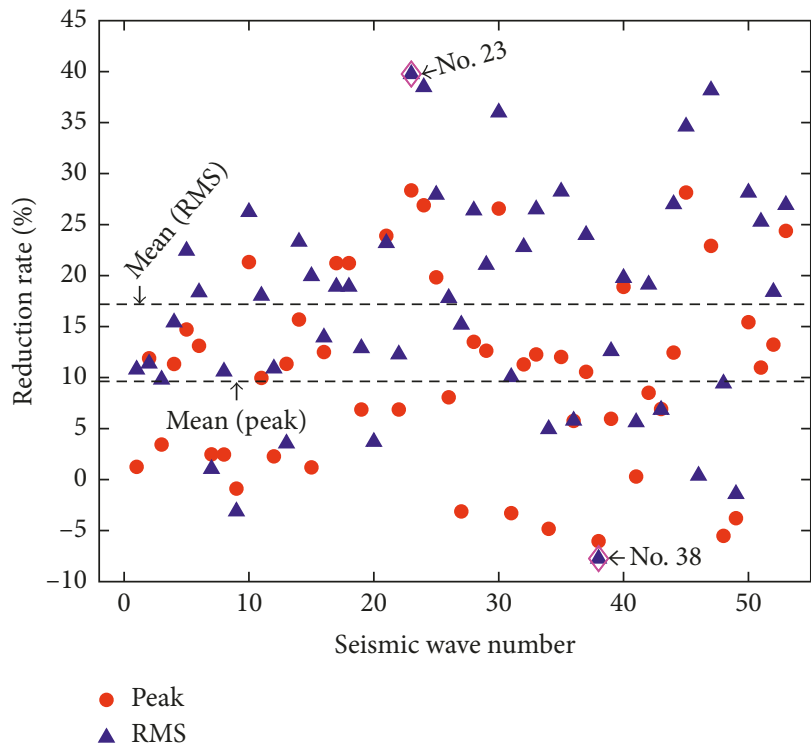

(a)

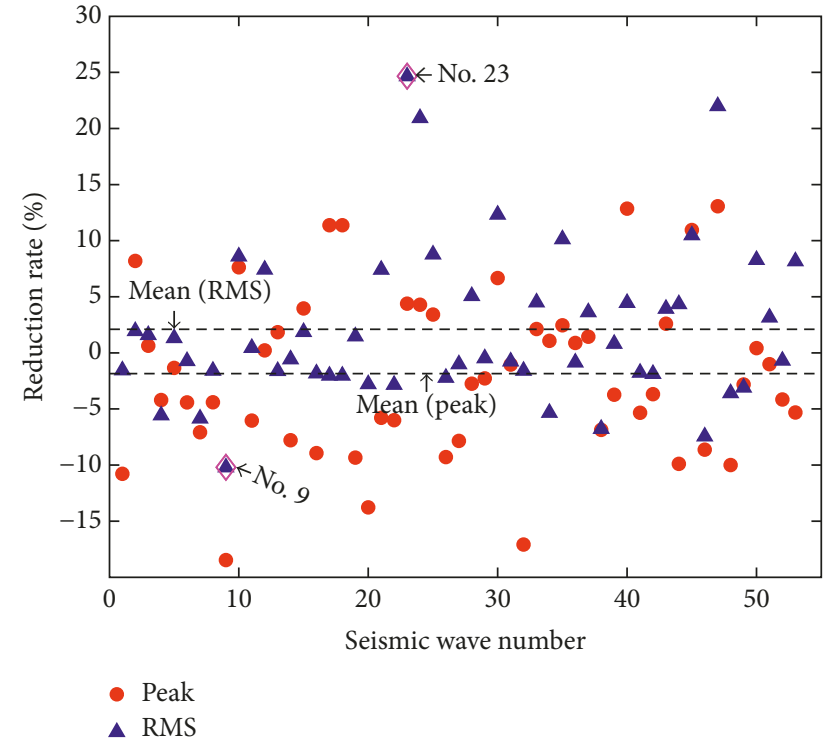

(b)

FIGURE 19: Reduction rates under 53 sets of seismic excitations. Reduction rates of (a) displacement and (b) acceleration.

(1) The parameter optimization design of CBDs for coalfired power plant structures can be conducted according to MTMD theory. The CBDs with optimized parameters exhibit good vibration control effects on the displacement response of a coal-fired power plant structure. At the same time, the acceleration control effect on the story containing the CBDs and the floors above shows good results, while that of the lower stories is poor. Overall, the seismic performance of the CBD-equipped structure evaluated in this research advances the potential engineering applications of this technology, and the CBD scheme adopted in this study provides a good reference for practical engineering design.

(2) The seismic response of a CBD-equipped structure under different seismic waves shows a certain discreteness. Under resonant conditions, that is, when the structural response is intense, the CBDs operate efficiently to provide vibration control. However, CBDs are less useful outside the resonant conditions, though the structural response is small in this situation. As a whole, the application of CBDs to improve the seismic performance of a power plant structure has a certain universal quality, regardless of the specific design of the plant.

(3) When the structural period deviates from the design period, whether because of structural changes, environmental factors, or damage from strong earthquakes, the CBD-equipped structure can maintain a certain damping effect compared to a more traditional structure, demonstrating that a CBDequipped coal-fired power plant structure can maintain robust damping behavior even when the structural period changes. 


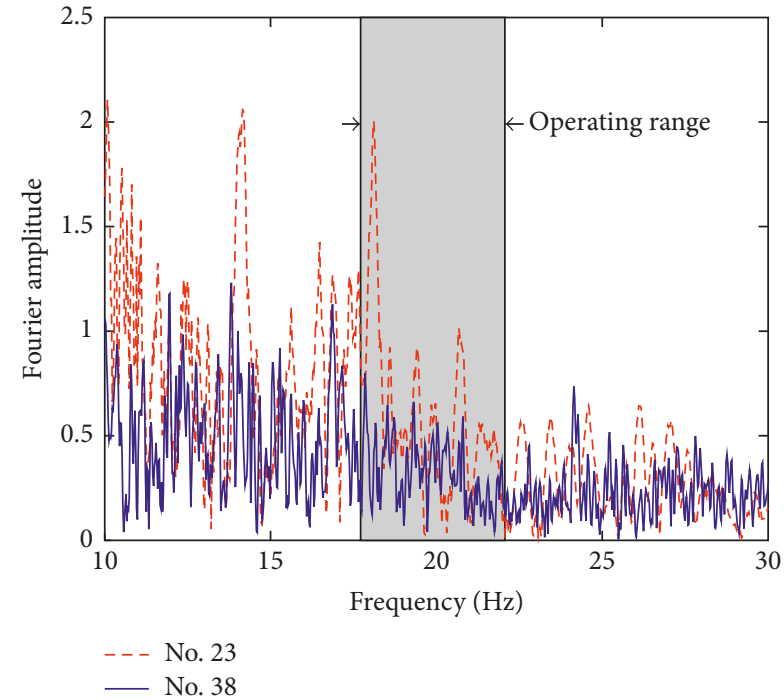

(a)
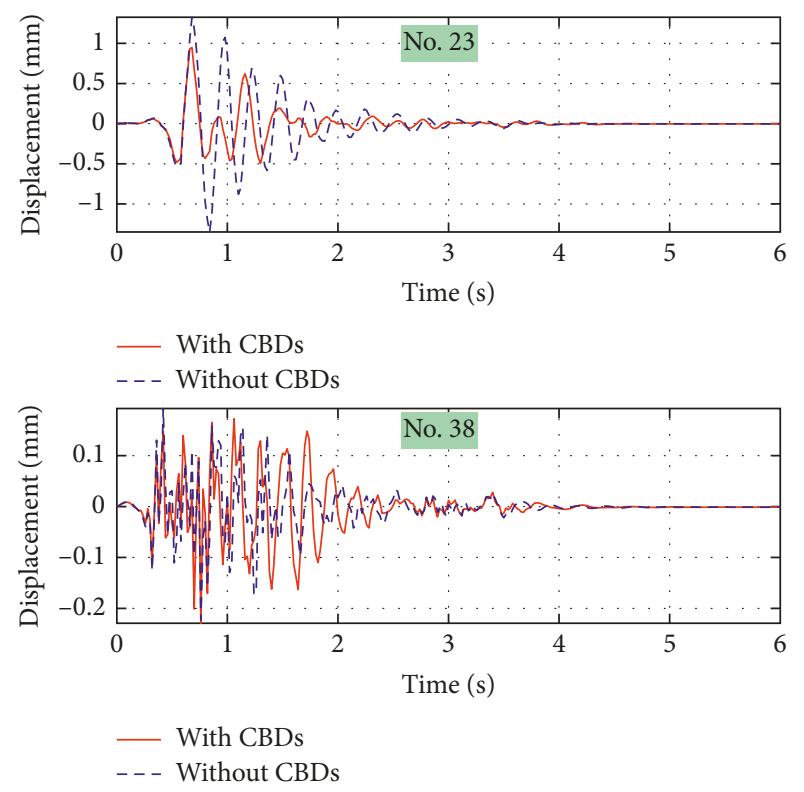

(b)

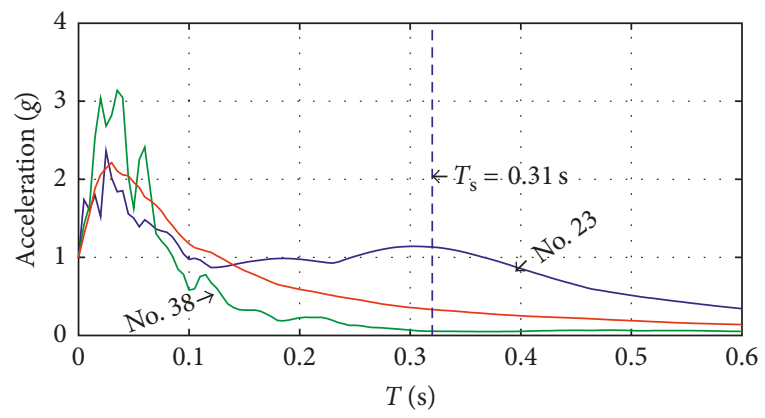

(c)

FIgURE 20: Reduction rates under 53 sets of seismic excitations. (a) Fourier amplitude spectrum of the 23rd and the 38th seismic excitations and the operating range of the structure with CBDs. (b) Comparison of interstory drift reduction rate between the 23rd and the 38th seismic excitations. (c) Response spectrum comparison between the 23rd and the 38th seismic excitations.

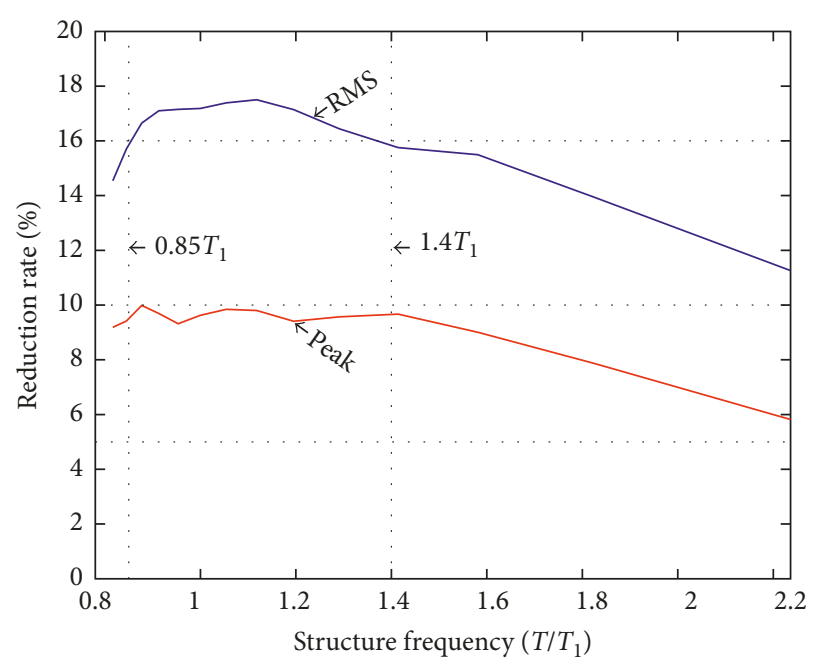

(a)

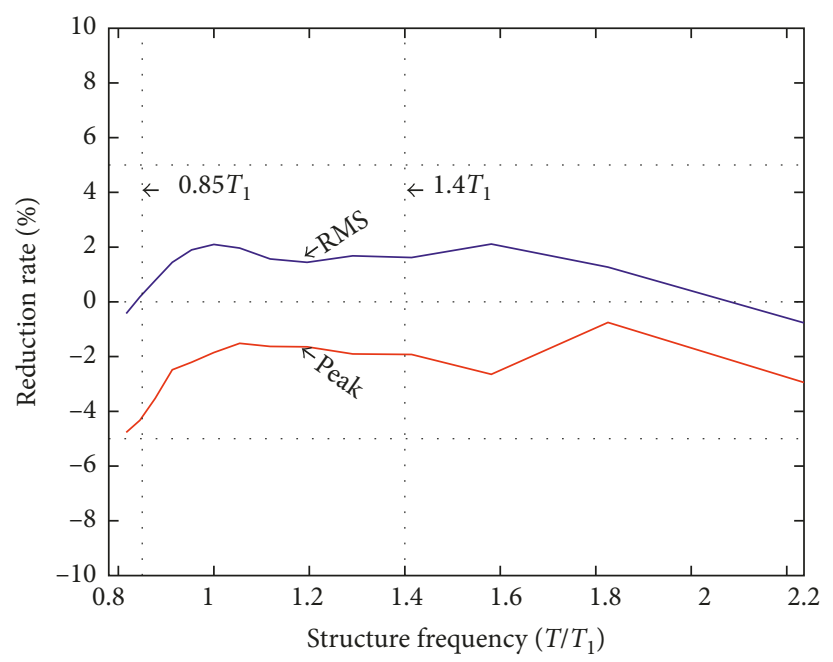

(b)

FIGURE 21: Reduction rates of (a) displacement and (b) acceleration with variation in structural frequency.

When applying the optimization method detailed in this article, the seismic response of coal-fired power plants equipped with CBDs is obviously improved. The control response of the structure under different seismic waves exhibits a certain discreteness. On one hand, this is because of the characteristics of TMD vibration control. On the other hand, this is due to the choice to ignore the control of high-order vibration modes. Considering these aspects, future research will involve achieving an improved damping effect using the multimode control of the CBD-equipped structure.

\section{Conflicts of Interest}

The authors declare that there are no conflicts of interest regarding the publication of this article.

\section{Acknowledgments}

This research was supported by Grant no. 51478023 from the National Natural Science Foundation of China. 


\section{References}

[1] B. J. Tang, R. Li, X. Y. Li, and H. Chen, "An optimal production planning model of coal-fired power industry in China: considering the process of closing down inefficient units and developing CCS technologies," Applied Energy, vol. 206, pp. 519-530, 2017.

[2] Z. Shu, S. Li, J. Zhang, and M. He, "Optimum seismic design of a power plant building with pendulum tuned mass damper system by its heavy suspended buckets," Engineering Structures, vol. 136, pp. 114-132, 2017.

[3] J. T. P. Yao, "Concept of structural control," Journal of the Structural Division, vol. 98, no. 7, pp. 1567-1574, 1972.

[4] T. Wu, G. Bai, and B. Liu, "Experimental study on seismic behavior of RC frame-bent structure of a large-scale power plant," Journal of Building Structures, vol. 28, no. 3, pp. 46-52, 2007, in Chinese.

[5] J. Den Hartog, Mechanical Vibrations, McGraw-Hill, New York, NY, USA, 1956.

[6] G. B. Warburton, "Optimum absorber parameters for various combinations of response and excitation parameters," Earthquake Engineering and Structural Dynamics, vol. 10, no. 3, pp. 381-401, 1982.

[7] H. C. Tsai and G. C. Lin, "Explicit formulae for optimum absorber parameters for force-excited and viscously damped systems," Journal of Sound and Vibration, vol. 176, no. 5, pp. 585-596, 1994.

[8] M. Gutierrez Soto and H. Adeli, "Tuned mass dampers," Archives of Computational Methods in Engineering, vol. 20, no. 4, pp. 419-431, 2013.

[9] C. C. Chang, "Mass dampers and their optimal designs for building vibration control," Engineering Structures, vol. 21, no. 5 , pp. $454-463,1999$.

[10] D. Wang, T. K. T. Tse, Y. Zhou, and Q. Li, "Structural performance and cost analysis of wind-induced vibration control schemes for a real super-tall building," Structure and Infrastructure Engineering, vol. 11, no. 8, pp. 990-1011, 2015.

[11] N. Longarini and M. Zucca, "A chimney's seismic assessment by a tuned mass damper," Engineering Structures, vol. 79, pp. 290-296, 2014.

[12] N. Hoang, Y. Fujino, and P. Warnitchai, "Optimal tuned mass damper for seismic applications and practical design formulas," Engineering Structures, vol. 30, no. 3, pp. 707-715, 2008.

[13] K. Xu and T. Igusa, "Dynamic characteristics of multiple substructures with closely spaced frequencies," Earthquake Engineering and Structural Dynamics, vol. 21, no. 12, pp. 1059-1070, 1992.

[14] H. Yamaguchi and N. Harnpornchai, "Fundamental characteristics of multiple tuned mass dampers for suppressing harmonically forced oscillations," Earthquake Engineering and Structural Dynamics, vol. 22, no. 1, pp. 51-62, 1993.

[15] T. Igusa and K. Xu, "Vibration control using multiple tuned mass dampers," Journal of Sound and Vibration, vol. 175, no. 4, pp. 491-503, 1994.

[16] R. S. Jangid and T. Datta, "Performance of multiple tuned mass dampers for torsionally coupled system," Earthquake Engineering and Structural Dynamics, vol. 26, no. 3, pp. 307-317, 1997.

[17] A. S. Joshi and R. S. Jangid, "Optimum parameters of multiple tuned mass dampers for base-excited damped systems," Journal of Sound and Vibration, vol. 202, no. 5, pp. 657-667, 1997.

[18] R. Rana and T. T. Soong, "Parametric study and simplified design of tuned mass dampers," Engineering Structures, vol. 20, no. 3, pp. 193-204, 1998.
[19] C. Li, "Performance of multiple tuned mass dampers for attenuating undesirable oscillations of structures under the ground acceleration," Earthquake Engineering and Structural Dynamics, vol. 29, no. 9, pp. 1405-1421, 2000.

[20] C. Li, "Optimum multiple tuned mass dampers for structures under the ground acceleration based on DDMF and ADMF," Earthquake Engineering and Structural Dynamics, vol. 31, no. 4, pp. 897-919, 2002.

[21] W. Tu and Y Zou, "Analysis of multistory structures with MTMD in frequency domain," Engineering Mechanics, vol. 20, no. 3, pp. 78-88, 2003.

[22] C. Li and Y. Liu, "Optimum multiple tuned mass dampers for structures under the ground acceleration based on the uniform distribution of system parameters," Earthquake Engineering and Structural Dynamics, vol. 32, no. 5, pp. 671-690, 2003.

[23] C. C. Lin, J. F. Wang, C. H. Lien, H. W. Chiang, and C. S. Lin, "Optimum design and experimental study of multiple tuned mass dampers with limited stroke," Earthquake Engineering and Structural Dynamics, vol. 39, no. 14, pp. 1631-1651, 2010.

[24] C. C. Lin and J. F. Wang, "Optimal design and practical considerations of tuned mass dampers for structural control," in Design Optimization of Active and Passive Structural Control Systems, Chapter 6, pp. 126-149, IGI global, Hershey, PA, USA, 2013.

[25] C. Lin, G. Lin, and C. Chiu, "Robust design strategy for multiple tuned mass dampers with consideration of frequency bandwidth," International Journal of Structural Stability \& Dynamics, vol. 17, no. 01, pp. 151-177, 2017.

[26] Z. Shu, S. Li, X. Sun, and M. He, "Performance-based seismic design of a pendulum tuned mass damper system," Journal of Earthquake Engineering, 2017, In press.

[27] S. He, L. Peng, N. Lin et al., "Research on bearing type coal scuttle of main power building in large thermal power plant in highly seismic region," Engineering Journal of Wuhan University, vol. 46, pp. 85-89, 2013, in Chinese.

[28] G. Chen and J. Wu, "Optimal placement of multiple tune mass dampers for seismic structures," Journal of Structural Engineering, vol. 127, no. 9, pp. 1054-1062, 2001.

[29] Y. Arfiadi and M. Hadi, "Optimum placement and properties of tuned mass dampers using hybrid genetic algorithms," International Journal of Optimization in Civil Engineering, vol. 1, no. 1, pp. 167-187, 2011.

[30] R. Frans and Y. Arfiadi, "Designing optimum locations and properties of MTMD systems," Procedia Engineering, vol. 125, pp. 892-898, 2015.

[31] T. Nagase and T. Hisatoku, "Tuned-pendulum mass damper installed in crystal tower," The Structural Design of Tall and Special Buildings, vol. 1, no. 1, pp. 35-56, 1992.

[32] J. Connor and S. Laflamme, Structural Motion Engineering, Springer International Publishing, New York, NY, USA, 2014.

[33] M. H. Chey and J. U. Kim, "Parametric control of structural responses using an optimal passive tuned mass damper under stationary Gaussian white noise excitations," Frontiers of Structural Civil Engineering, vol. 6, no. 3, pp. 267-280, 2012.

[34] R. Soto-Brito and S. E. Ruiz, "Influence of ground motion intensity on the effectiveness of tuned mass dampers," Earthquake Engineering and Structural Dynamics, vol. 28, no. 11, pp. 1255-1271, 1999.

[35] GB 50011-2010, Code for Seismic Design of Buildings, Ministry of Construction, General Administration of Quality Supervision, Inspection and Quarantine, Beijing, China, 2010.

[36] C. C. Lin, J. F. Wang, and J. M. Ueng, "Vibration control identification of seismically excited m.d.o.f. structure-PTMD 
systems," Journal of Sound and Vibration, vol. 240, no. 1, pp. 87-115, 2001.

[37] CSI, CSI Analysis Reference Manual for SAP2000, ETABS, SAFE and CSiBridge, Computers and Structures, Inc., Berkeley, CA, USA, 2015.

[38] ATC 63, Quantification of Building Seismic Performance Factors (Report ATC-63), Applied Technology Council, Redwood City, CA, USA, 2010. 


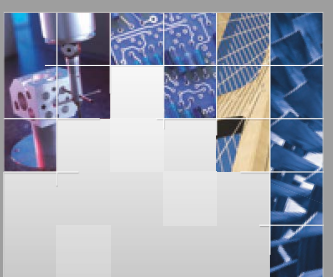

\section{Enfincering}
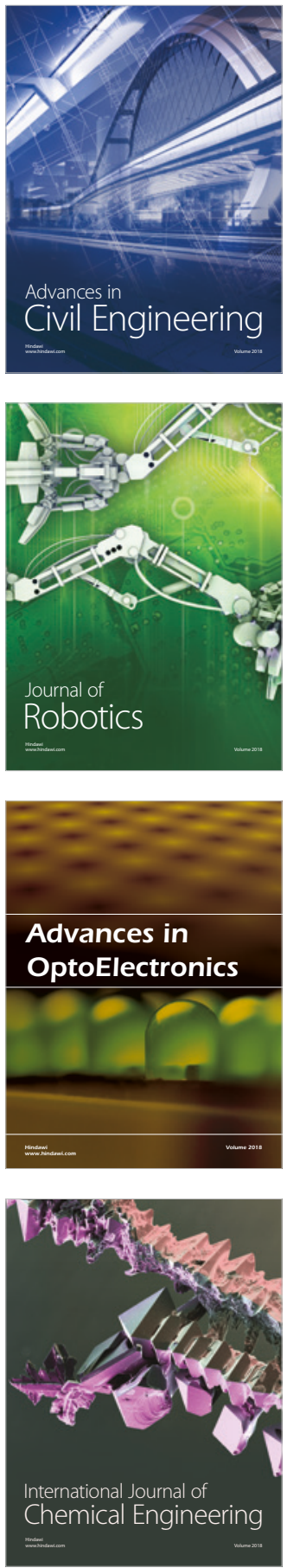

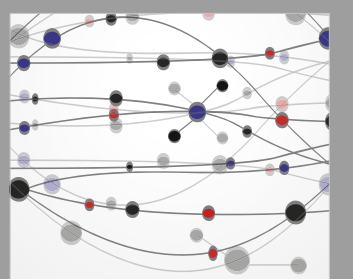

\section{Rotating \\ Machinery}

The Scientific World Journal

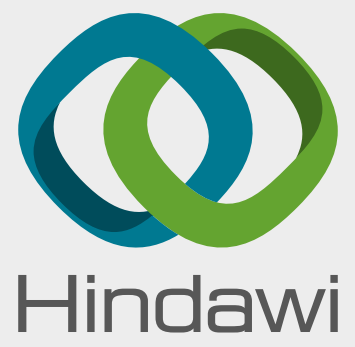

Submit your manuscripts at

www.hindawi.com
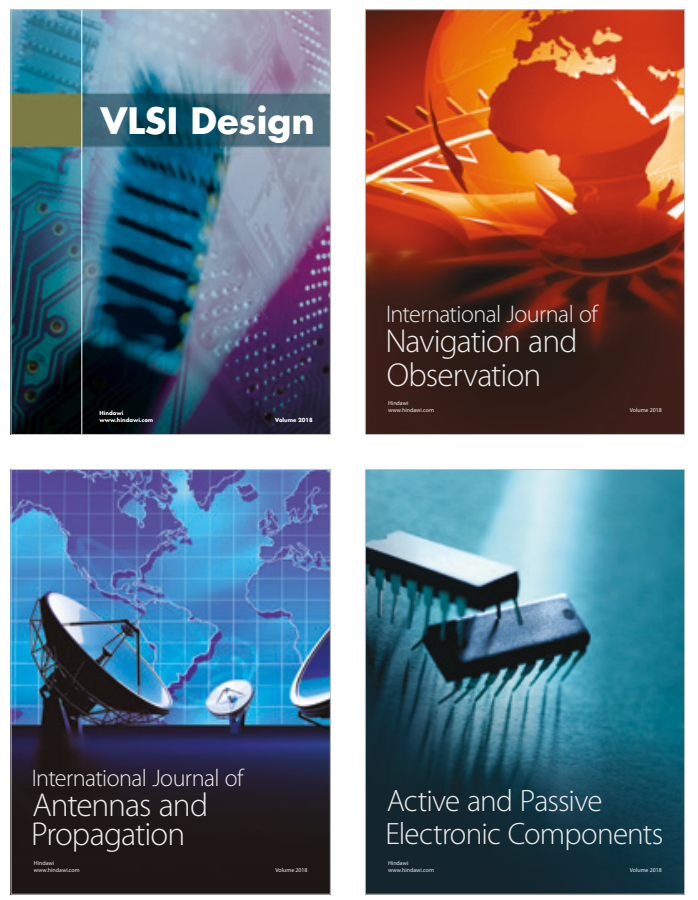
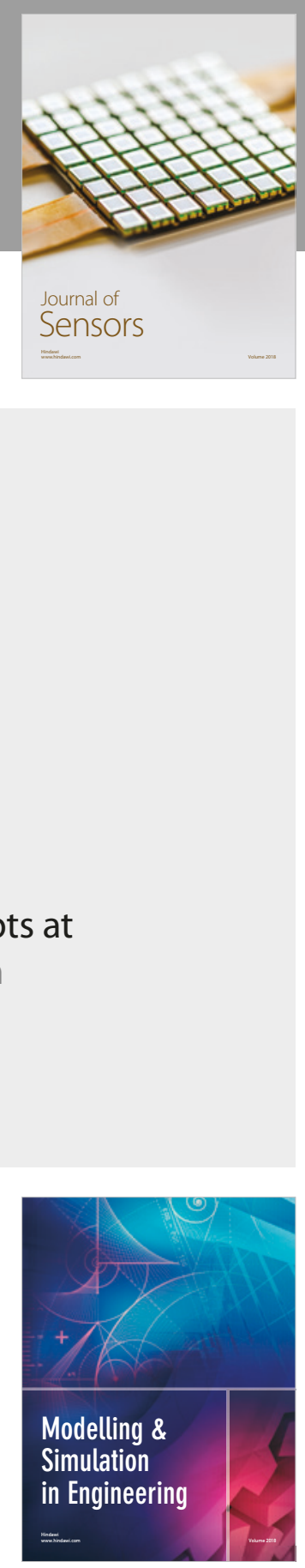

\section{Advances \\ Multimedia}
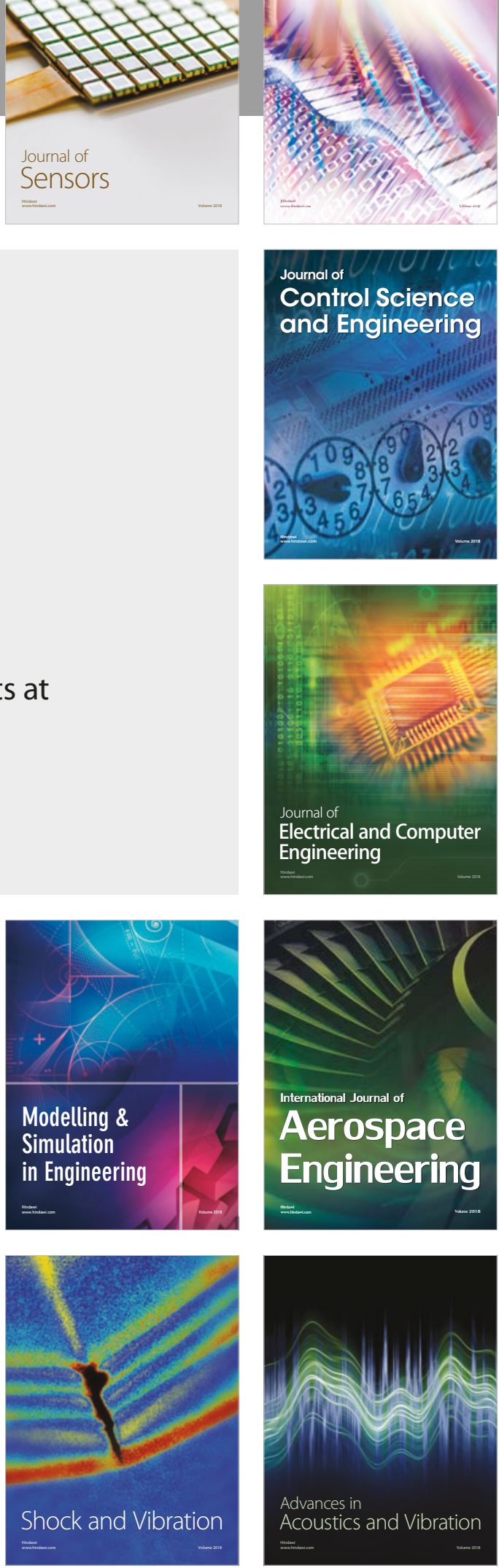